\title{
تأثير بعض هن أدوات الإنتاج الرشيق في اختيار إستراتيجية الايصاء الواسع (بحث استطلاعي تصليلي في الشركة العراقية لصناعة وتجارة الكارتون ومستلزماتها و شركة صناعات الاصباغ الحديثة)
}

\author{
م.د. عفاف حسن هادي الساعاتي الباحثة : نور قصي عبد الرزاق \\ كلية الإدارة والاقتصاد/ جامعة بغداد : نور
}

المستخلص

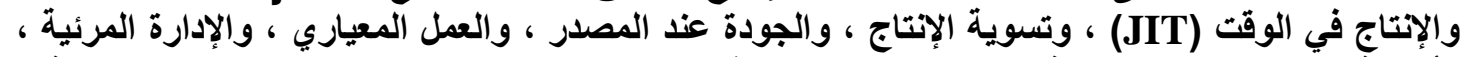

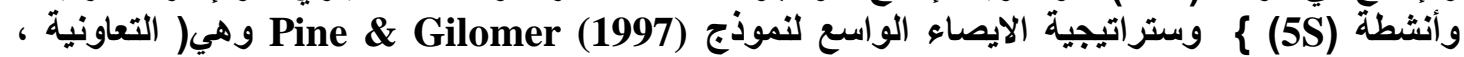

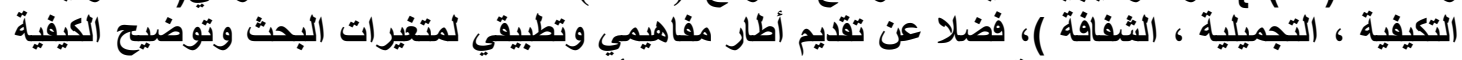

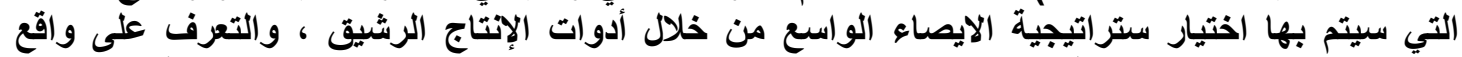

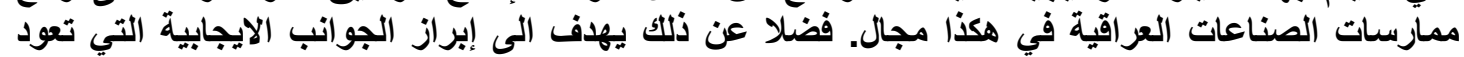

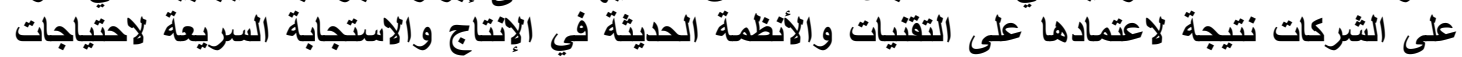

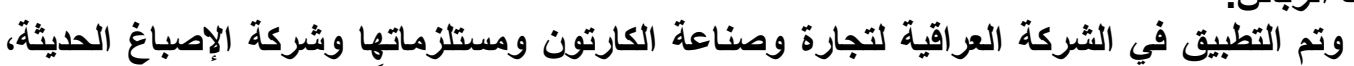

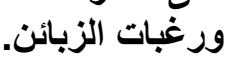

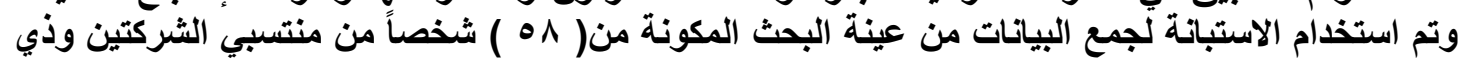

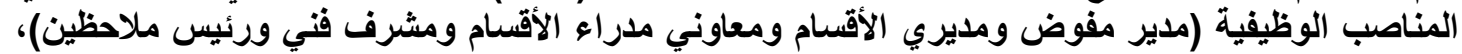

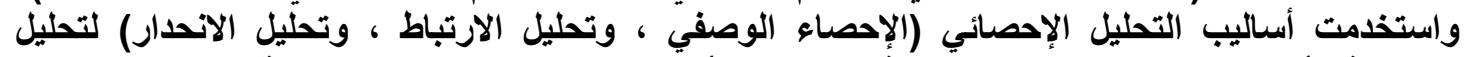

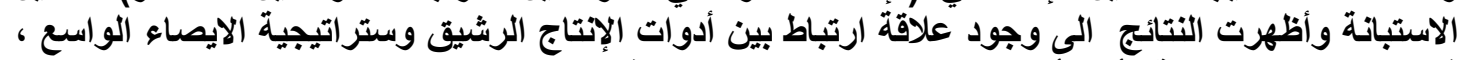

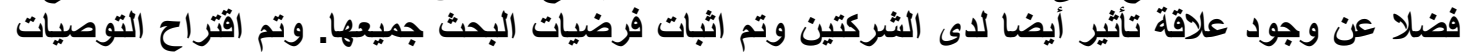

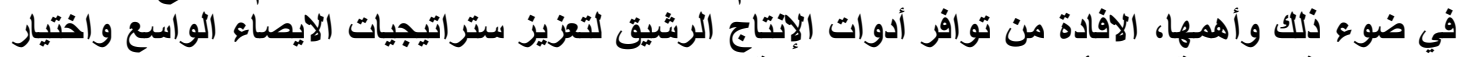

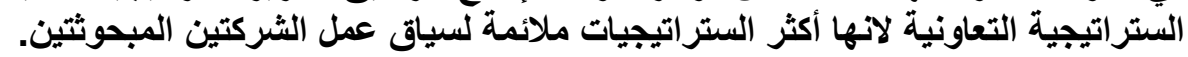

المطات الرئيسية لابحث/ أدوات الإتتاج الرشيق- ستراتيجيات الايصاء الواسع .

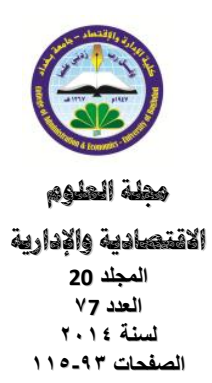




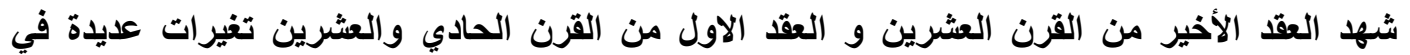

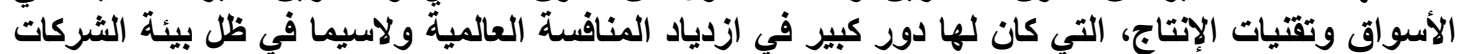

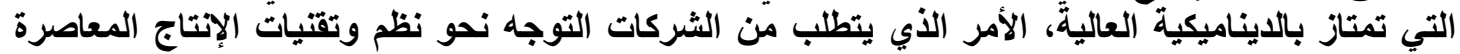

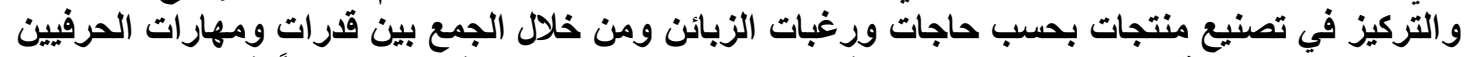

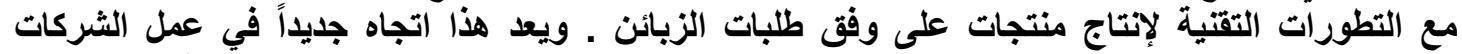

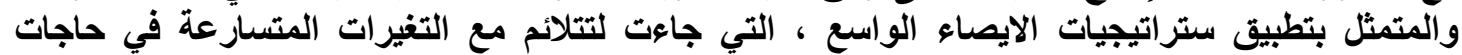

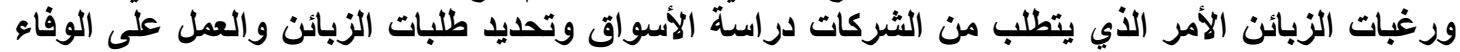

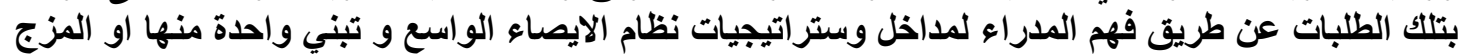

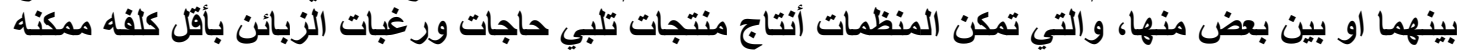

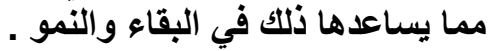

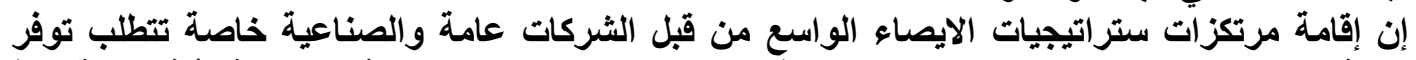

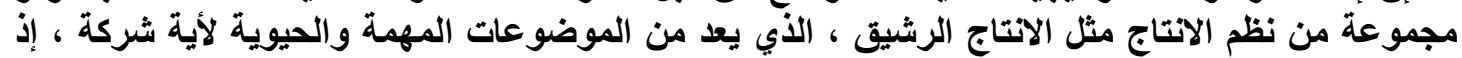

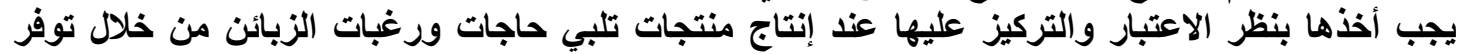

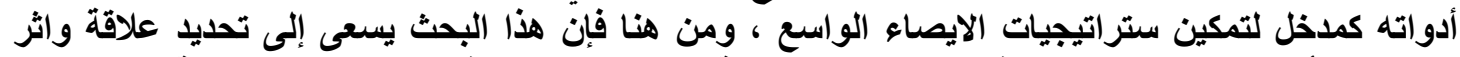

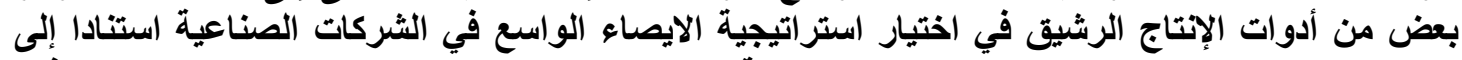

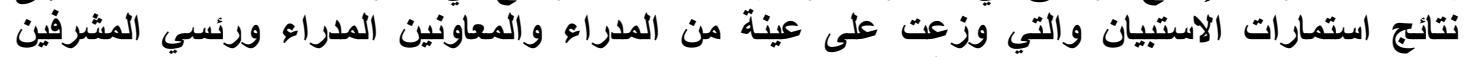

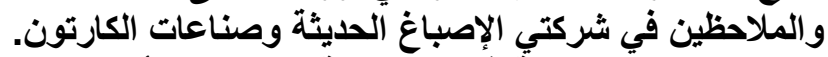

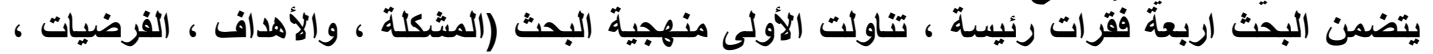

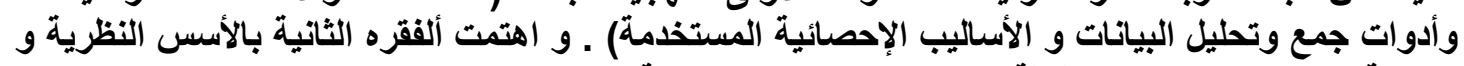

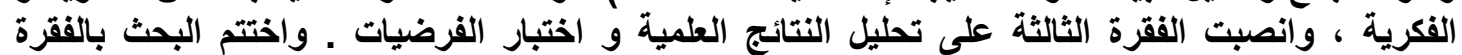

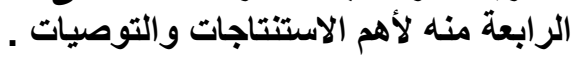

I. هشكلة البمث : اخذ موضوعا ستراتيجيات الايصاء الواسع ( Mass Customization

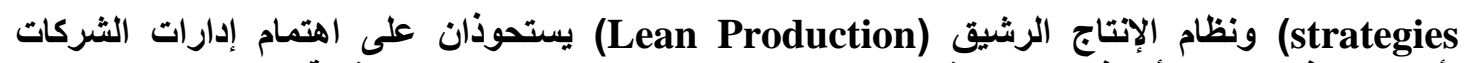

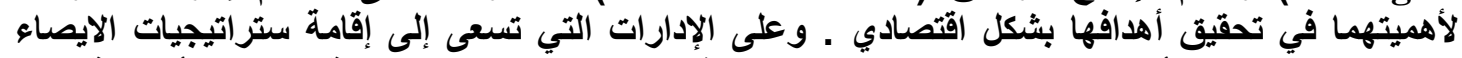

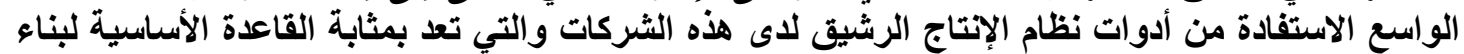

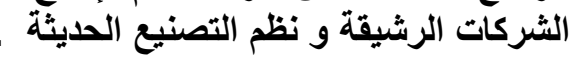

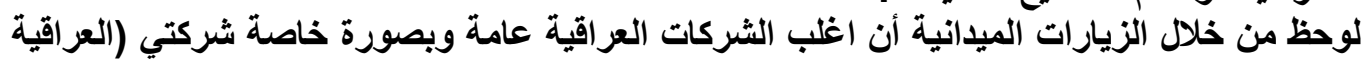

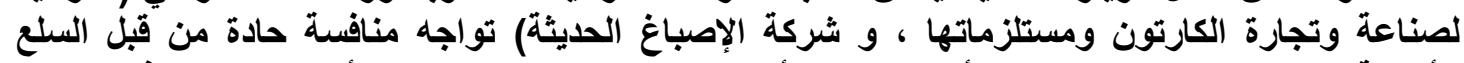

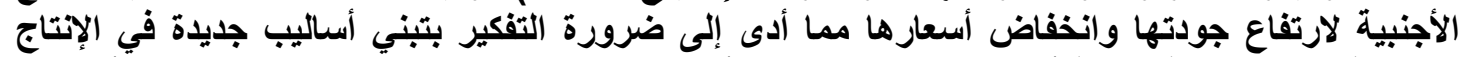

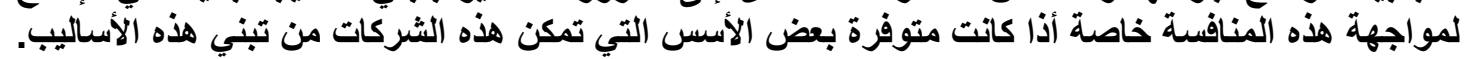

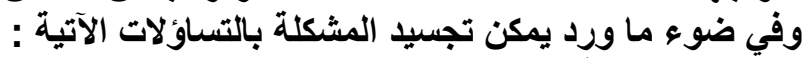
1) " هل تتوافر أدوات الإنتاج الرشيق في الثركتين المبحوثنين؟

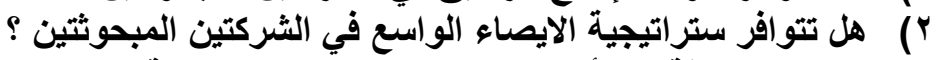

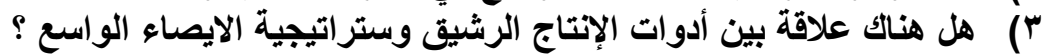

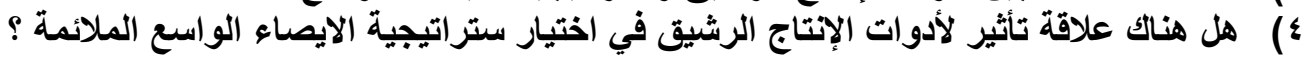

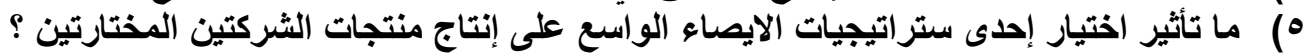




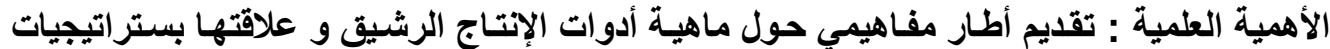

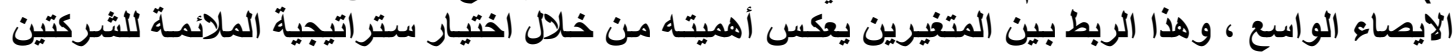
المبحوثثين بواسطة أدوات الإنتاج الرشيق.

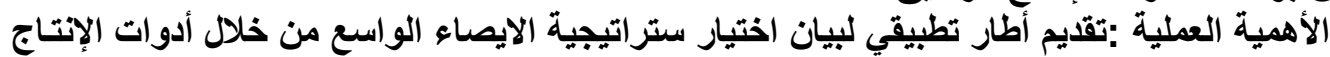

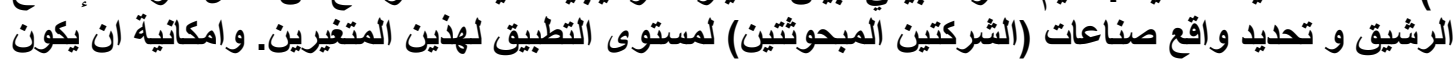

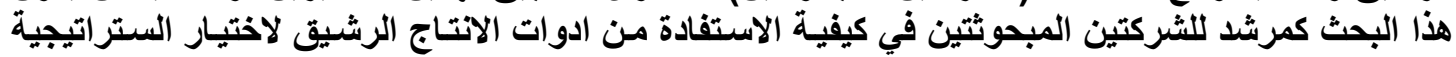

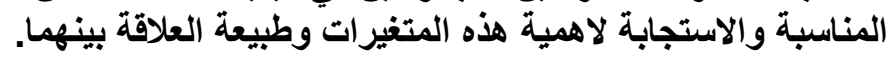
r r ا ـ اهمية البحث : في ضوء تحديد المشكلة فان أهداف البحث تنصب على ما يأتي : (1) الثخيص وتحديد العلاقة والأثر بين أدوات الإنتاج الرشيق وستراتيجيات الايصاء الواسع في الثركتين

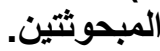
r r بشخيص مستوى الاهمية والاستخدام لأدوات الإنتاج الرشيق في الثركتين المبحوثثين.

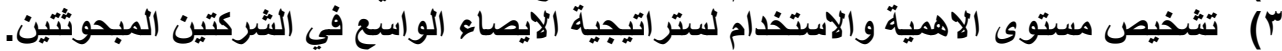

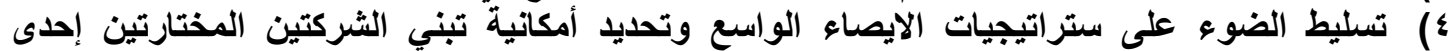

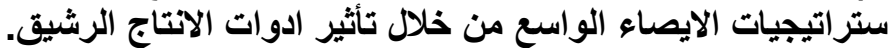

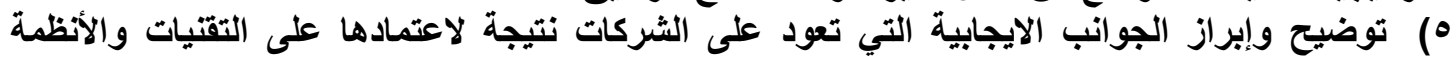

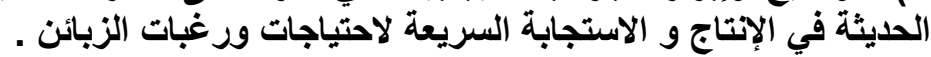

ع. نمهوذج البحث وفرضياته : تنطلب المعالجة المنهجية لمشكلة البحث في ضوء إطارها النظري

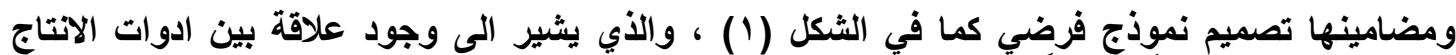

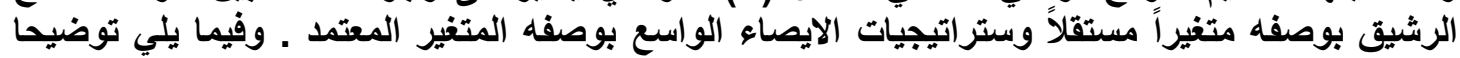

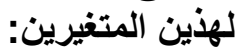

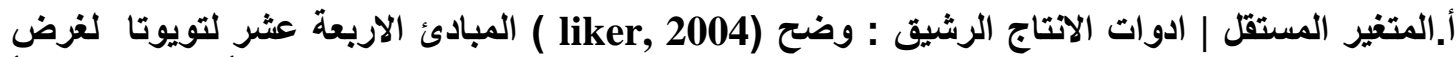

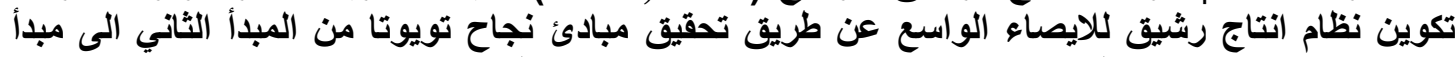

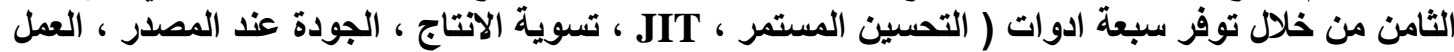

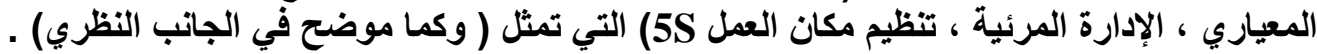

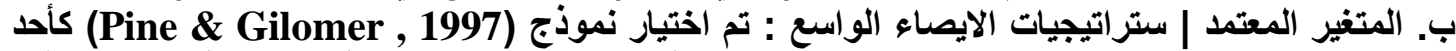
نماذج ستراتيجيات الايصاء الواسع (الذي يتكون من اربعة ستراتيجيات : التعاونية ، التكيفية ، التجميلية ، الثفافة ) وذللك للاسباب الاتية :

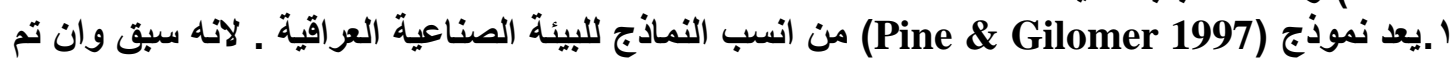

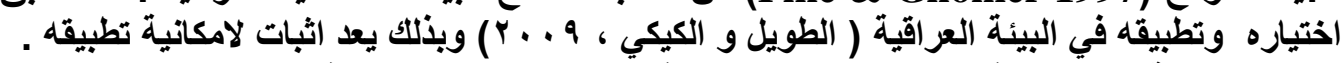

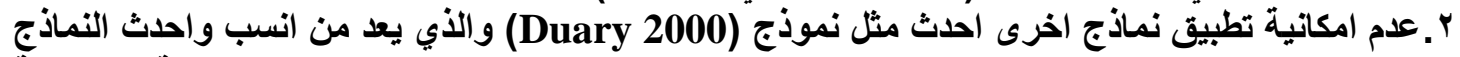

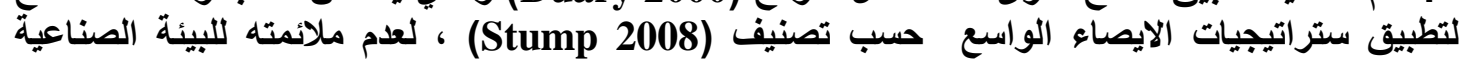
العراقية وللاسباب الآتية : الآيصاء

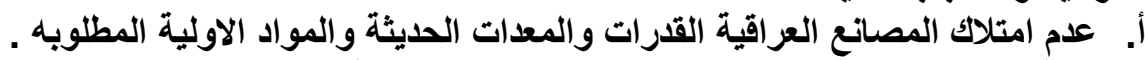

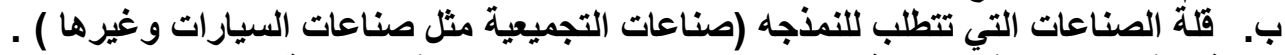

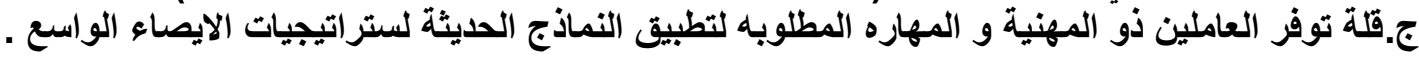




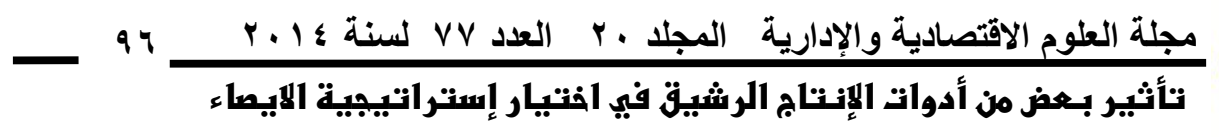

الواسع (بـث استطلاعي تصليلي في الشركة العراقية لصناعة وتنجارة

الكارتون ومستلززماتها و شركة صناعات الاصبا غ اللديثة)

شكل (1 ) يوضح النموذج الفرضي

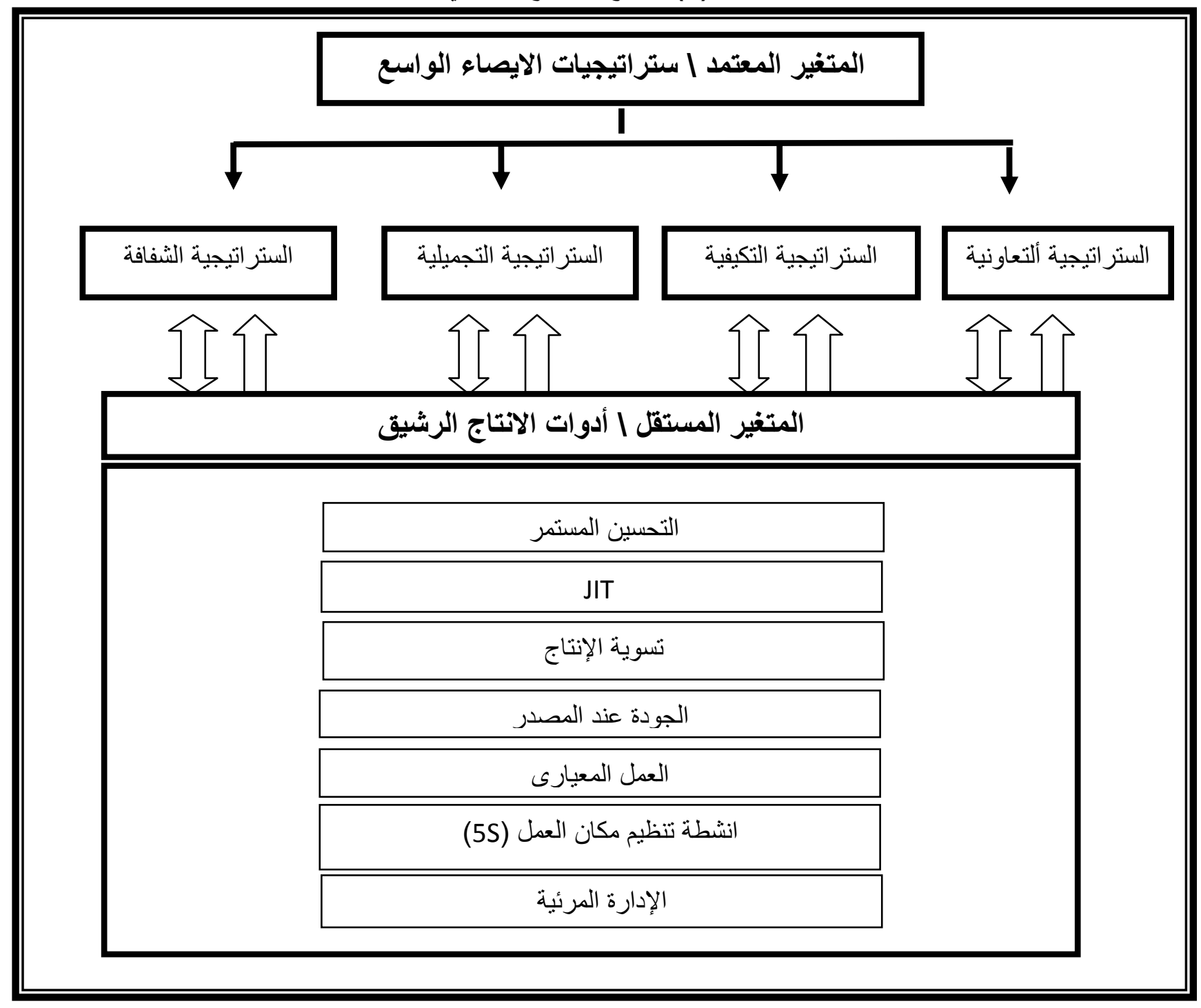

اما الفرضيات فقد صيغت فرضيات البحث بناءا على مخطط البحث الفرضي (انموذج البحث) و كما مبين

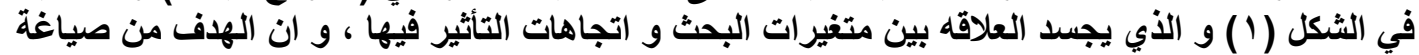

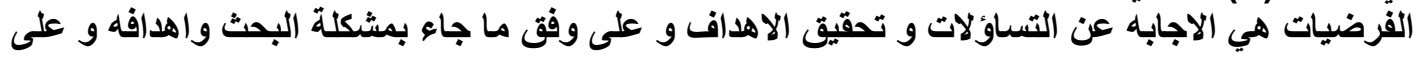

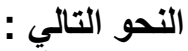

ا ـالفرضية الاولى : توجد علاقة ارتباط ذات دلالة معنوية بين ادوات الانتاج الرشيق و الستراتيجية التعاونية. r .الفرضية الثانية : توجد علاقة ارتباط ذات دلالة معنوية بين أدوات الانتاج الرشيق و الستراتئية التيجية التكيفية.

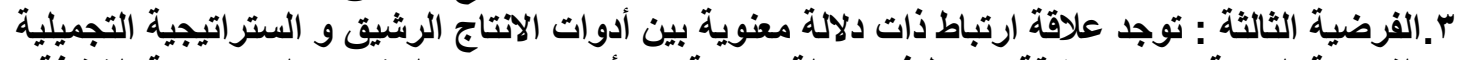

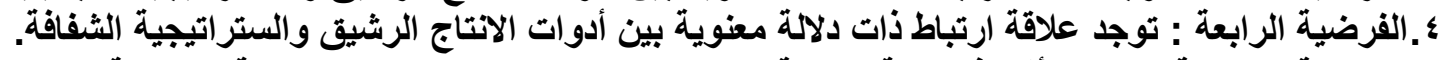

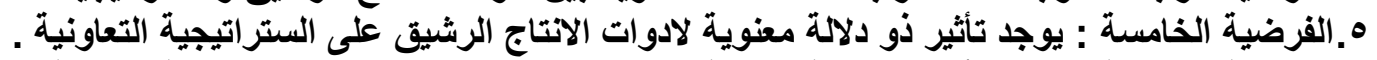

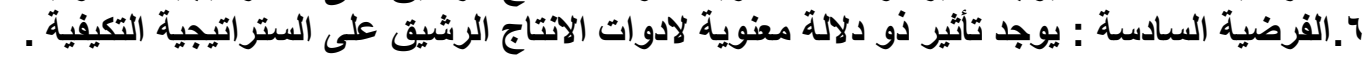

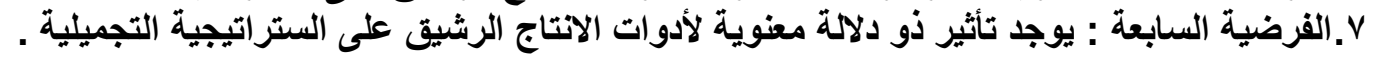




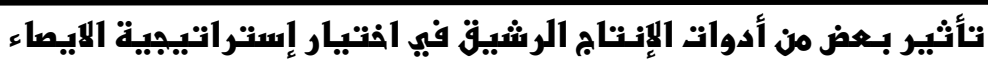

الواسع (بحث استطلا عي تصليلي في الشركة العراقية لصناعة وتجارة

الكارتون ومستنلزماتها و شركة صنا عات الاصباغ العديثة)

^.الفرضية الثامنة : يوجد تأثير ذو دلالة معنوية لأدوات الانتاج الرشيق على الستراتيجية الثفافة .

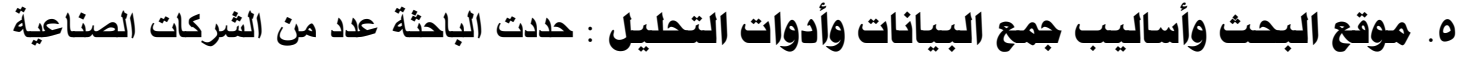

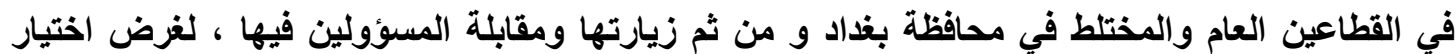

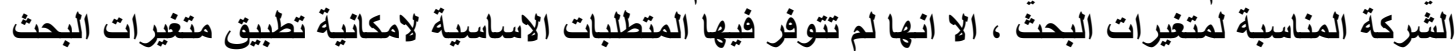

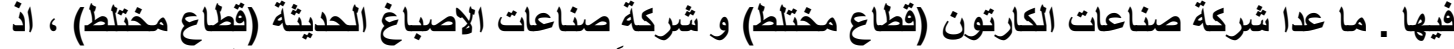

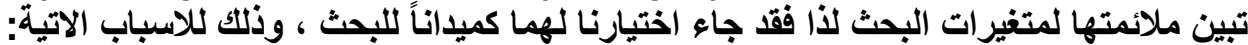

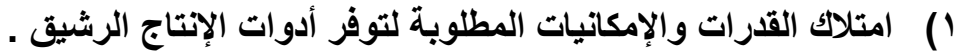

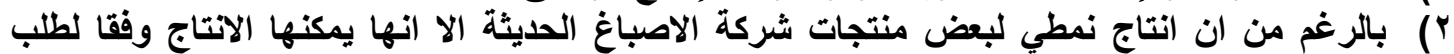

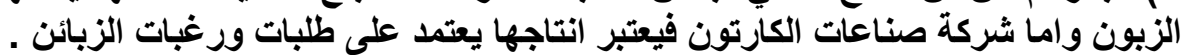

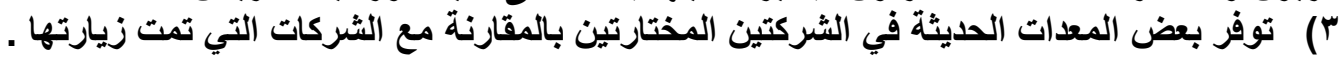

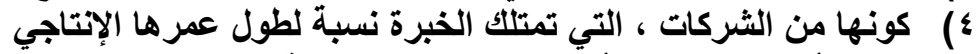

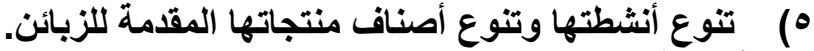

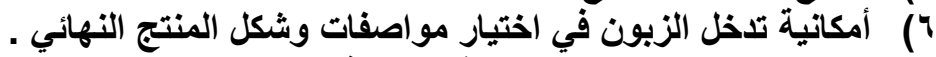

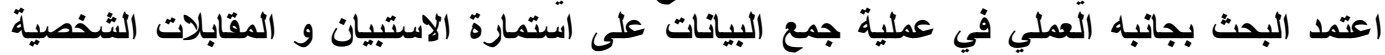

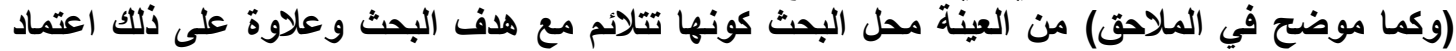

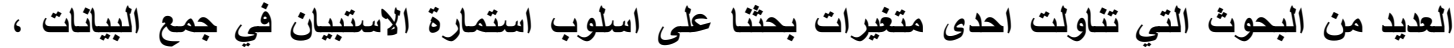

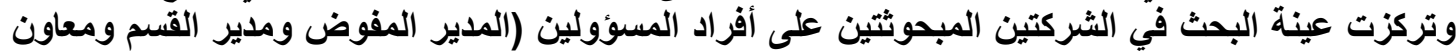

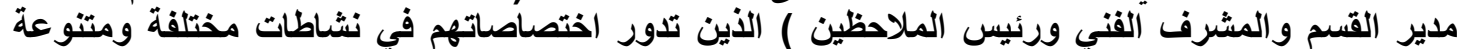

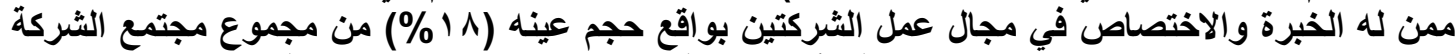

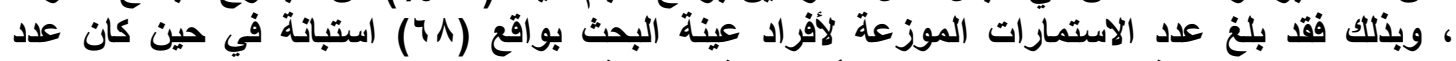

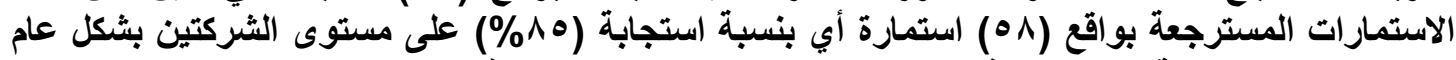

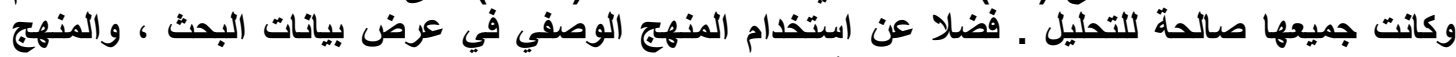

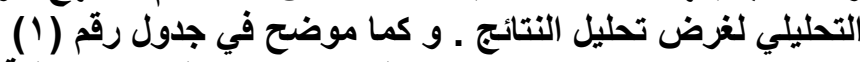
جدول (1) يوضح البيانات الاولية لعينة البحث

\begin{tabular}{|c|c|c|c|c|c|c|}
\hline المجموع & مشيرف & ملاحظين & معاون مدير & قدم & مفوض مدير & \\
\hline$Y \varepsilon$ & $r$ & $\wedge$ & $\mathrm{V}$ & • & 1 & شركة صناعات الكارتون \\
\hline$r \varepsilon$ & $\Lambda$ & 0 & 11 & 9 & 1 & شركيثة صناعات الإصباغ \\
\hline
\end{tabular}

الثبات صدق الاستبيان والمقياس كان من خلال الأتي :

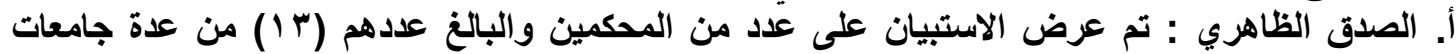

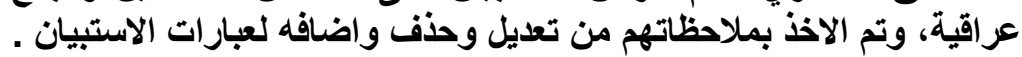

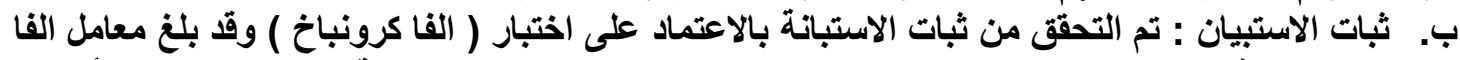

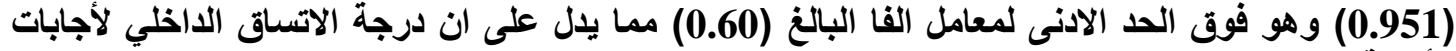
الأسئلة عالي جدا. ج.صدق المقياس : اما بصدد صدق المقياس فيكون من خلال تربيع قيمة ثبات الاستبانة والتي ستكون نتيجة

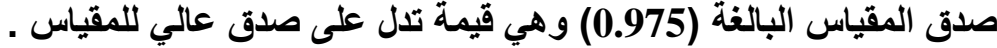


الاسايب الاحصائية التي تم استخدامها في البحث وبالاستناد على استخدم البرنامج الإحصائي (Spss)

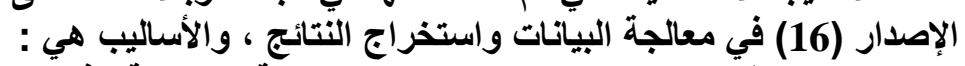

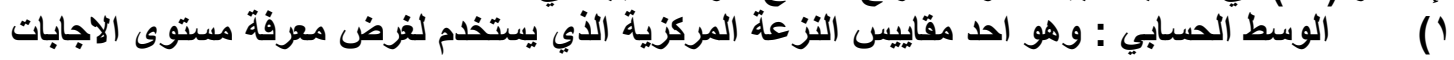
حول كل متنير

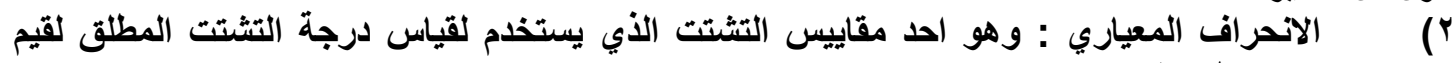

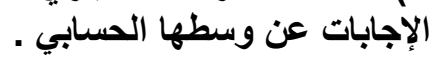

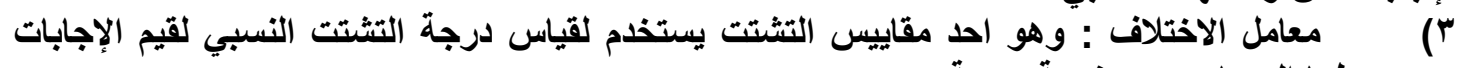

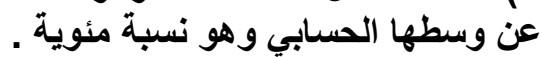

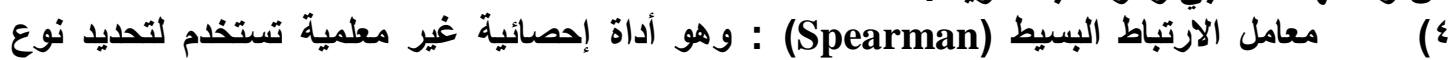
العلاقة بين متغيرات البحث في المخطط الفربط الفرضي لقياس الارتباط.

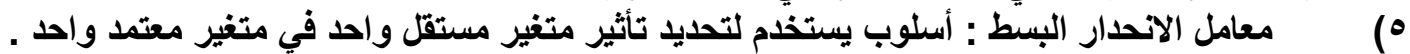

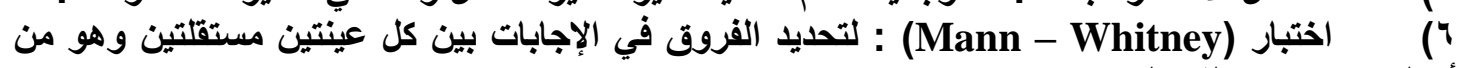

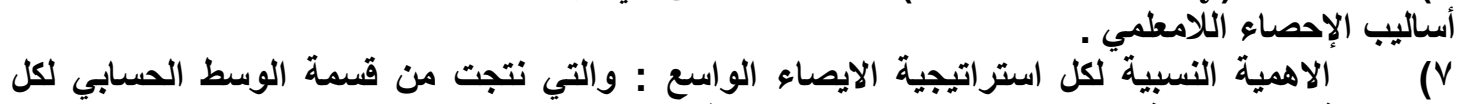

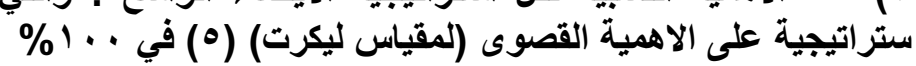

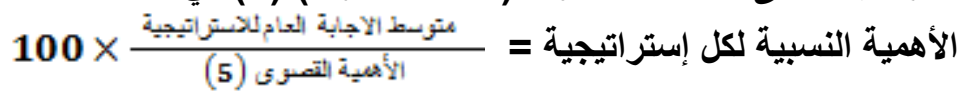

\section{ثانيا : هرتكرات نظرية}

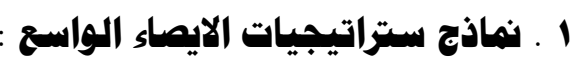

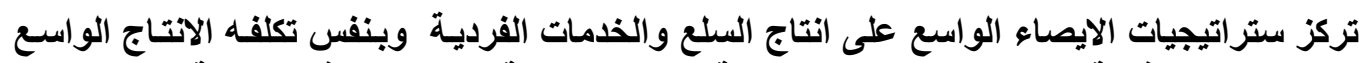

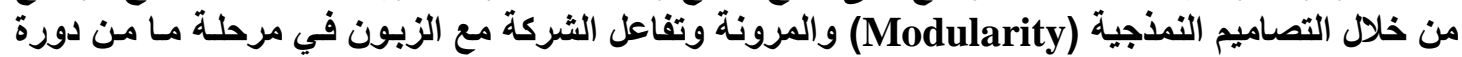
Matulik, (Christensen, 2012 : 1 ( الانتاج جناج

: (2008 : 23-28

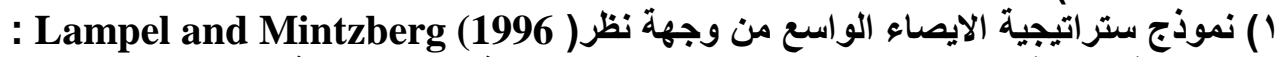

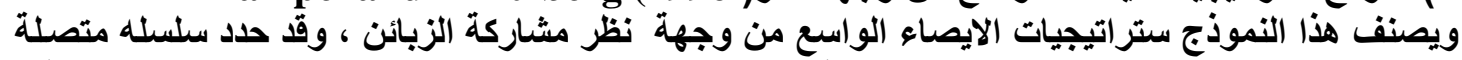

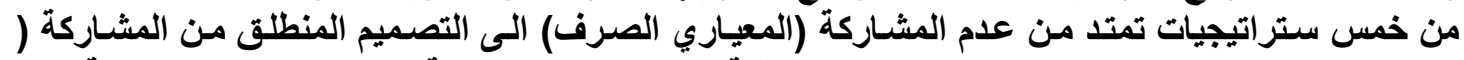

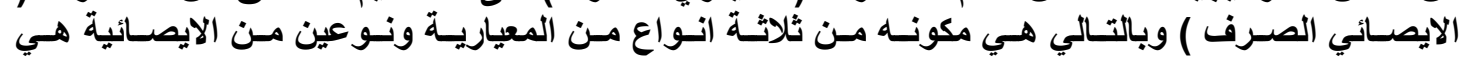

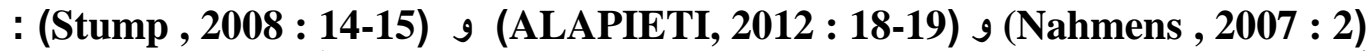

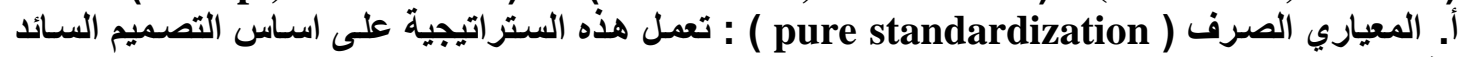

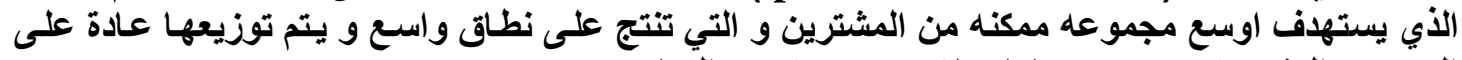

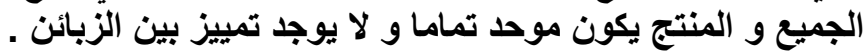

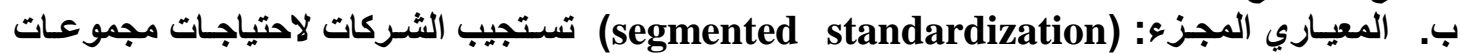

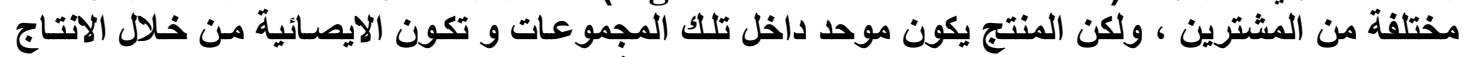

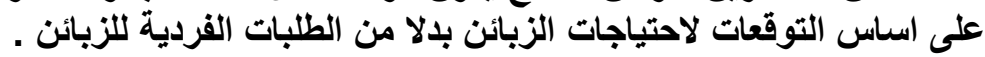

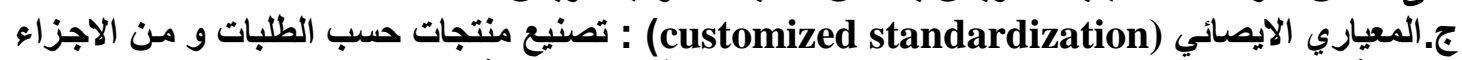

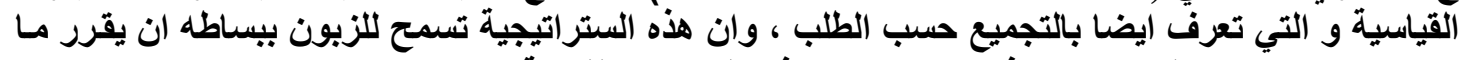

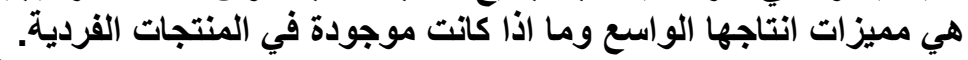

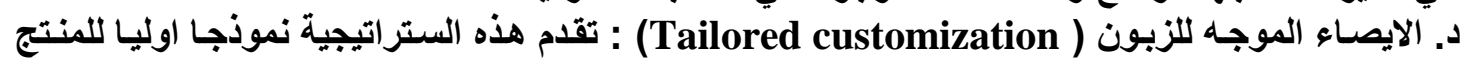

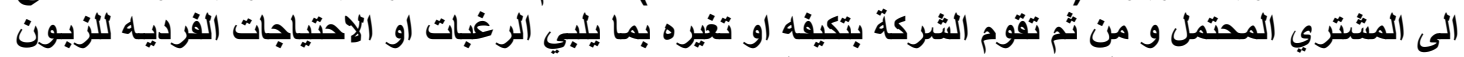

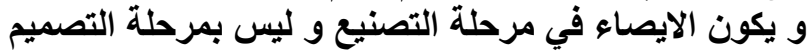

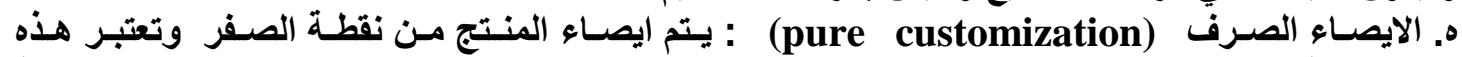

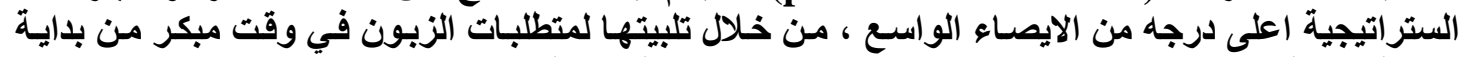

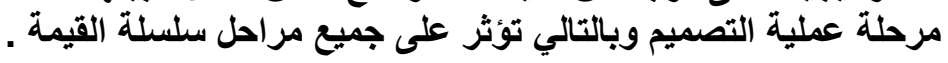




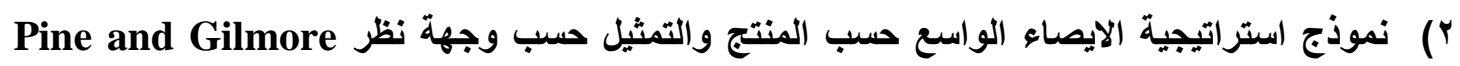

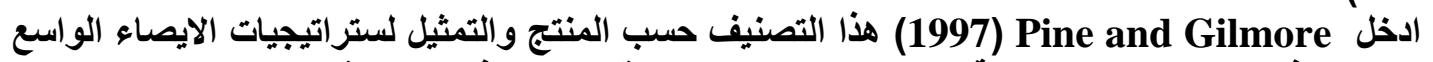

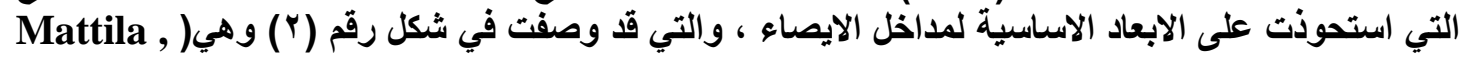

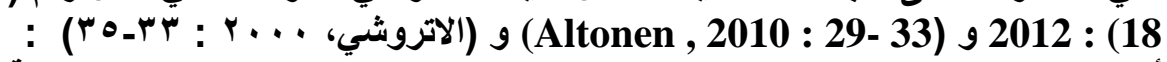

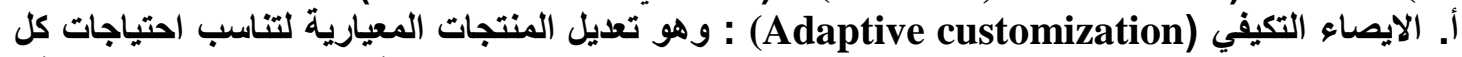

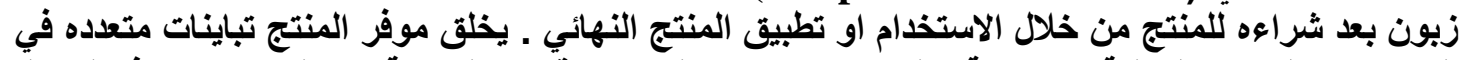

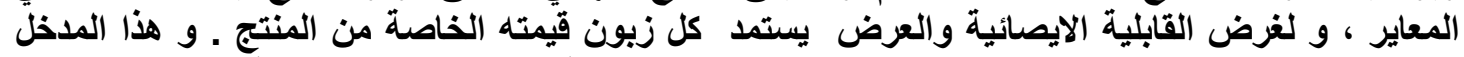

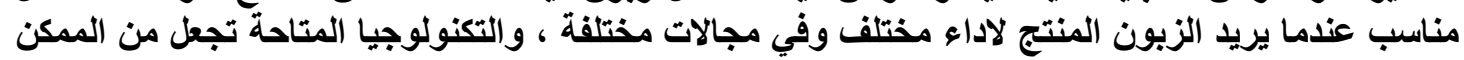

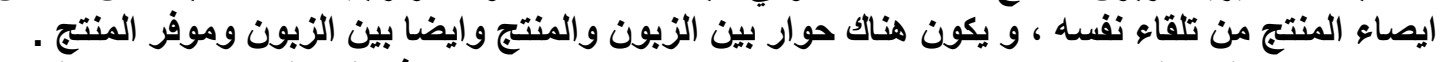

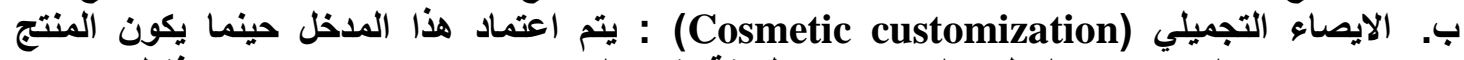

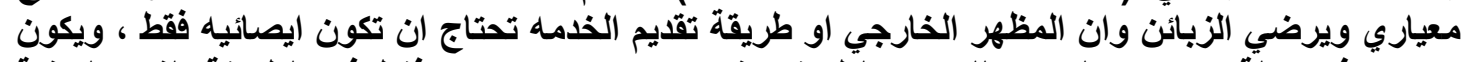

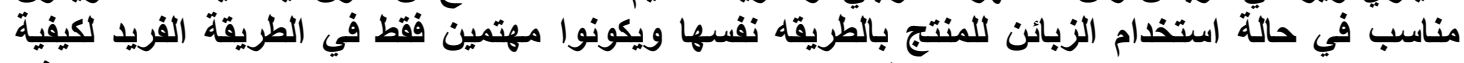

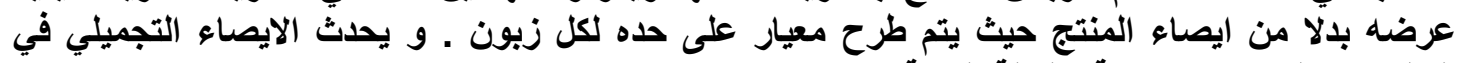

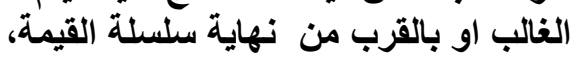

شكل ( r ) يوضح ستر اتيجيات الايصاء الواسع ل(1997) Pine and Gilmore) المعلدهل)

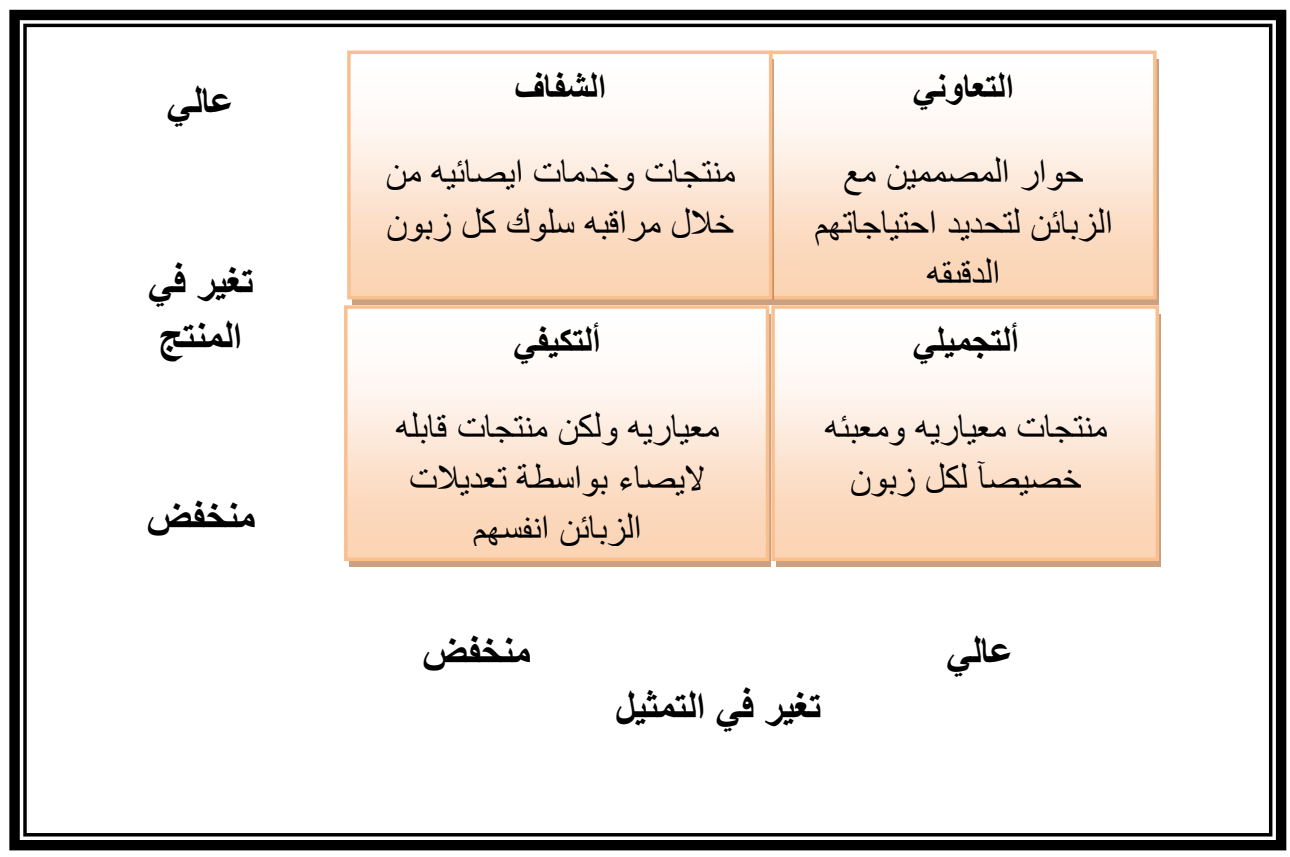

Source : Riihimaa, Jaakko\& Ruohonen, Mikko\& Mäkipää, Marko, 2004, Transitions in Mass Customization Strategies Requirements for Information Systems, FRONTIERS OF E-BUSINESS RESEARCH $2004: 376$

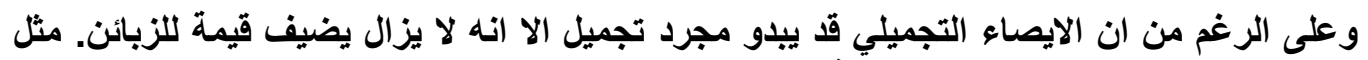

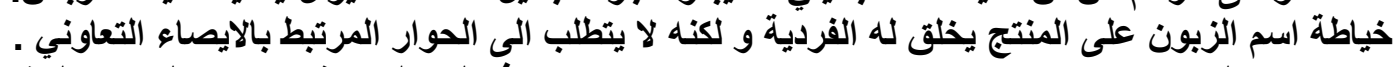

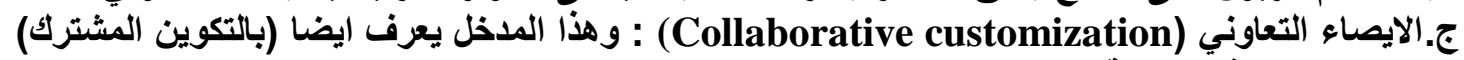

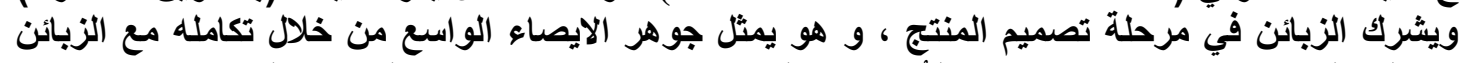

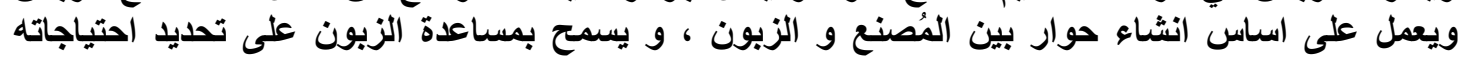




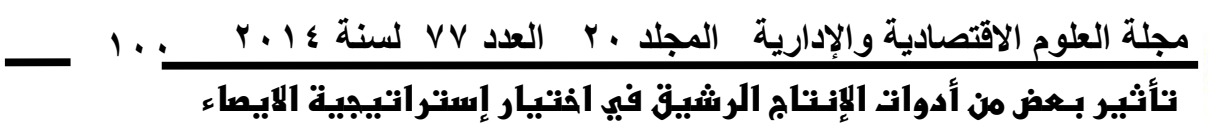

الواسع (بـث استطلا عي تصليلي في الشركة العراقية لصناعة وتتجارة

الكارتون ومستنلزماتها و شركة صنا عات الاصباغ الهديثة)

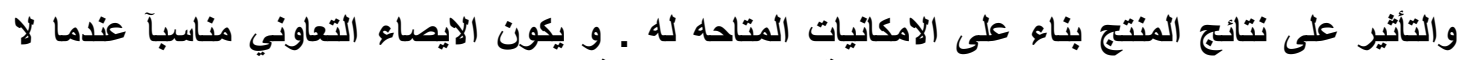

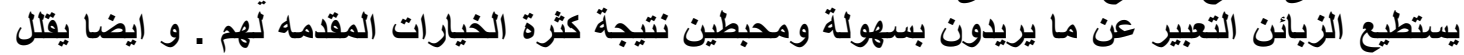

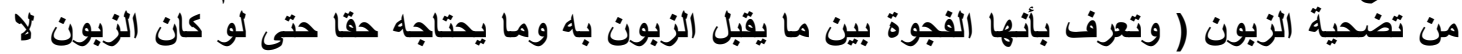

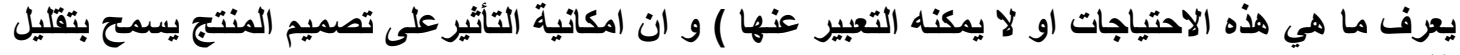
د. الايصاء الثفاف (Transparent customization) : يوفر للزبائن المنتجات او الخدمات الفرديه

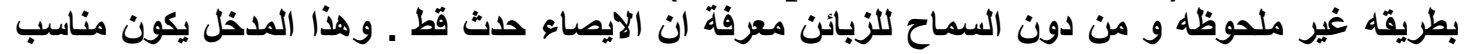

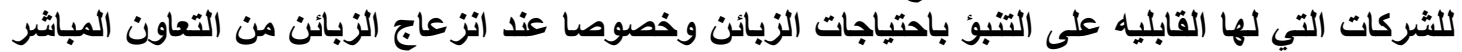

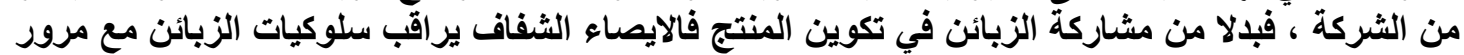

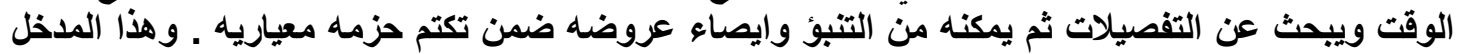

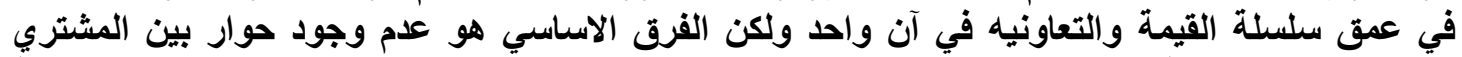

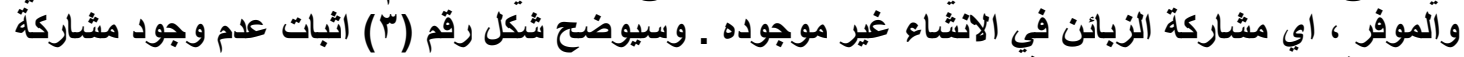

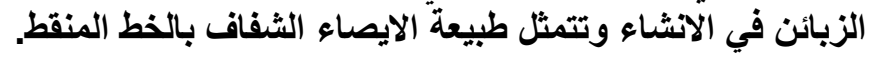

$$
\text { شكل (ץ") يوضح مداخل ومستويات الايصاء الواسع }
$$

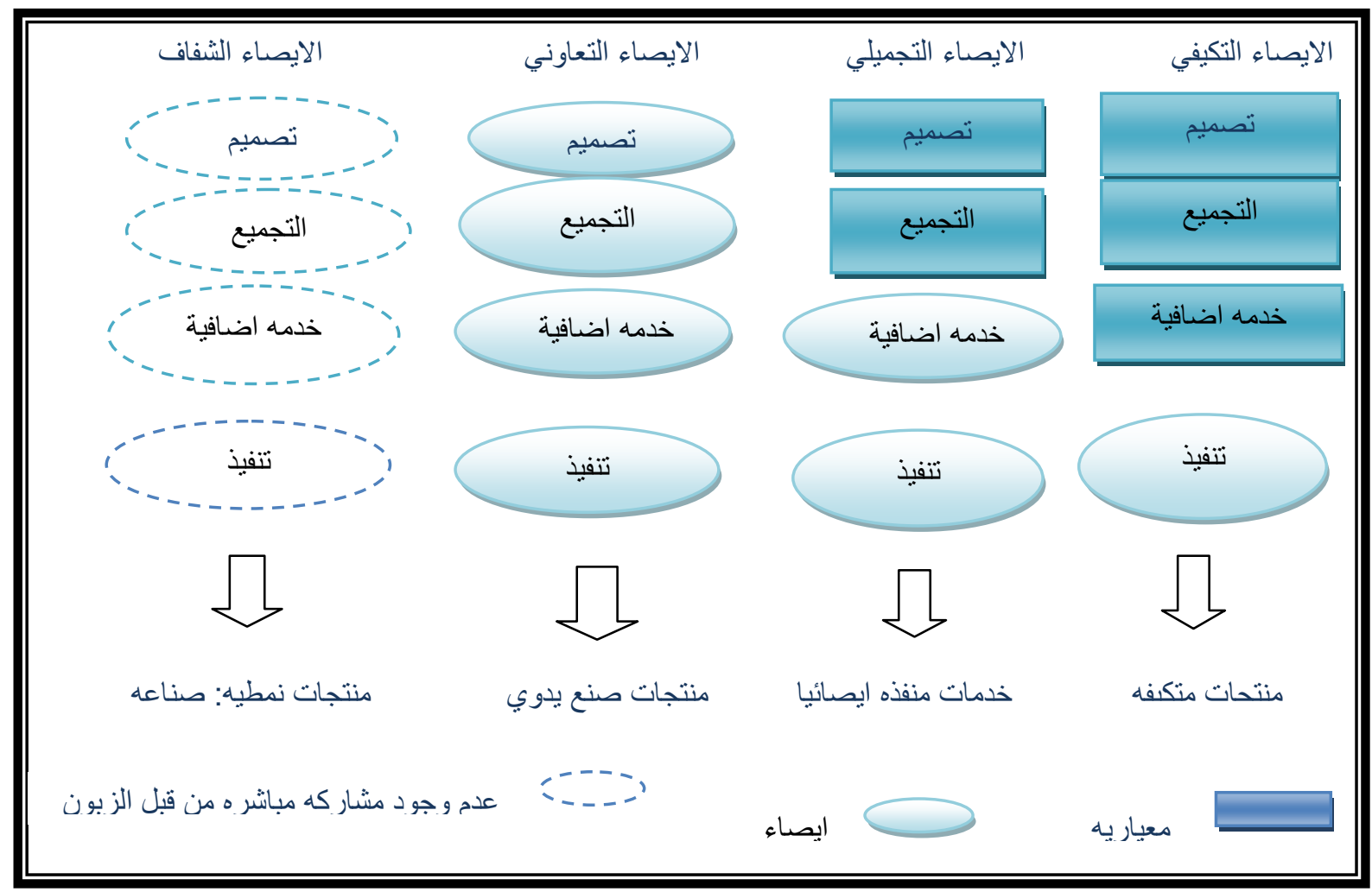

Source : Aiste Altonen,2011, Success Factors of Mass Customization Cases: Chocri and Shoes of Prey, Department of Management and International Business Aalto University School of Economics , P : 33

r) نمهوذج استراتيجية/لايصاء الواسع هن وجهة نظر العملية ل . Duray et al (2000):

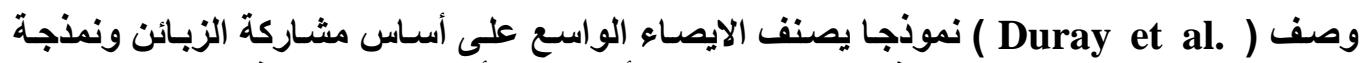

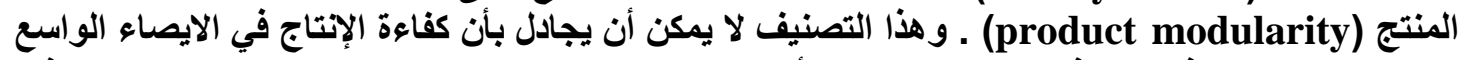

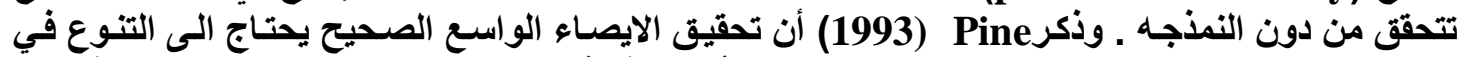

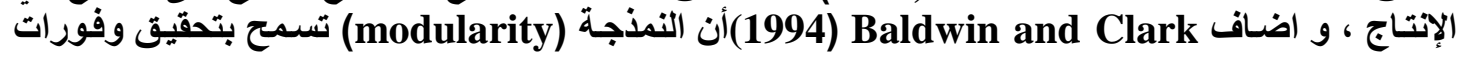




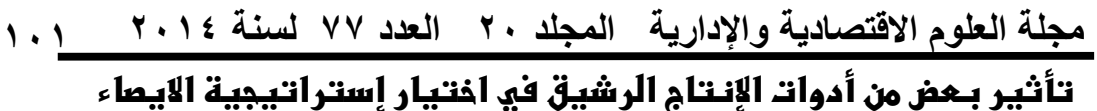

الواسع (بـث استطلاعي تهليلي في الشركة العراقية لصناعة وتنجارة

الكارتوز ومستلزماتها و شركة صنا عات الاصباغ العديثة)

الحجم والنطاق عبر خطوط الإنتاج ، و ثم اقترح . McCutcheon et al (1994) أن تصميم وحدات المنتج

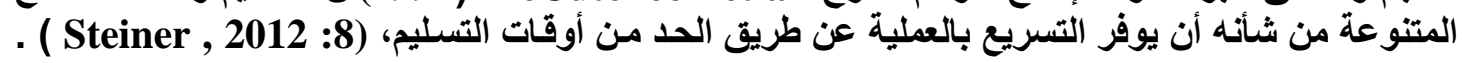

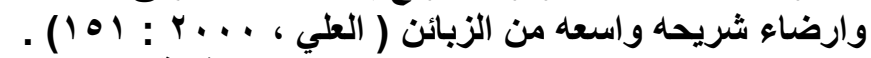

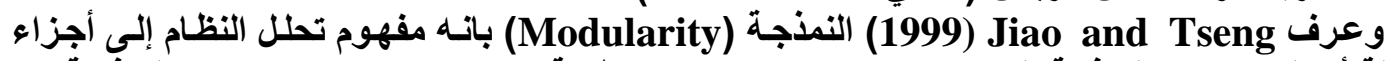

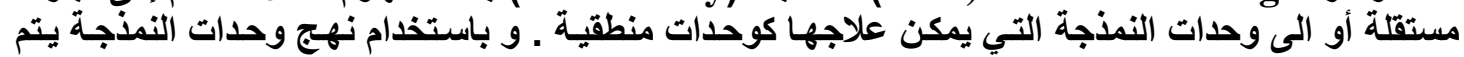

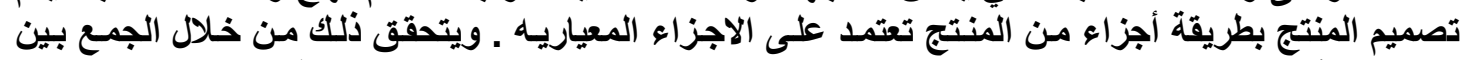

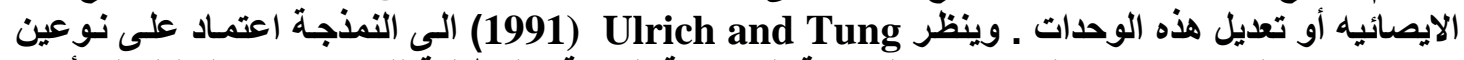

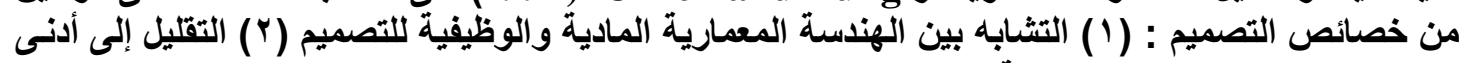

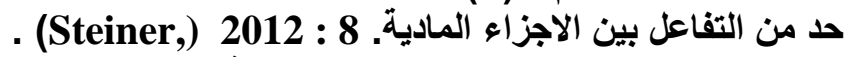
و يصنف .

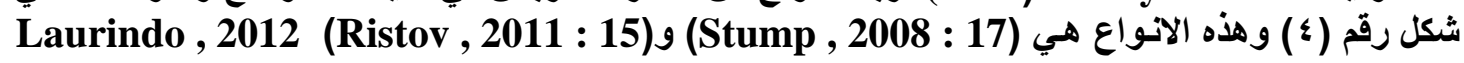
: (Kissimoto \& : 2)

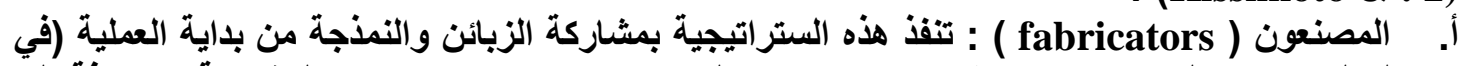

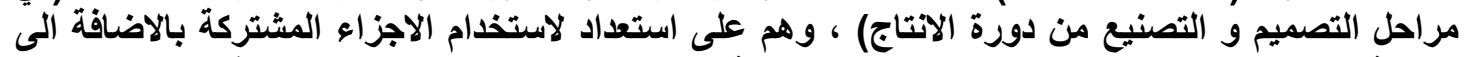

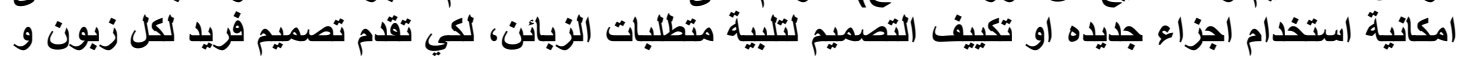

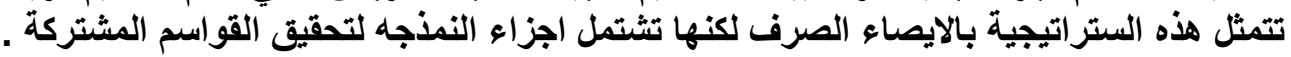

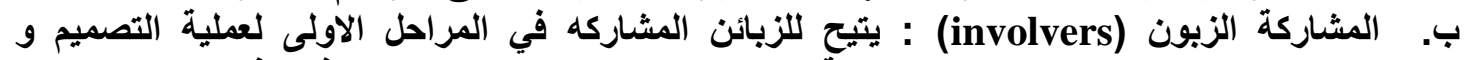

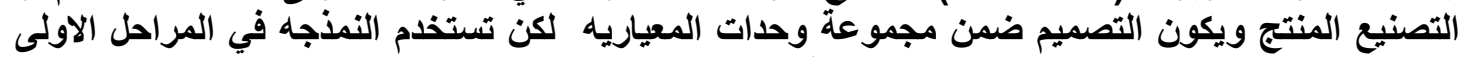

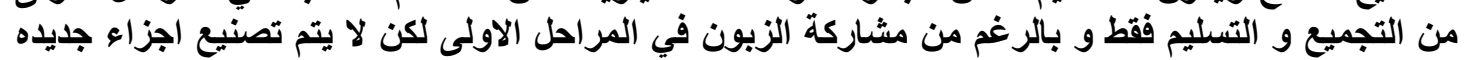

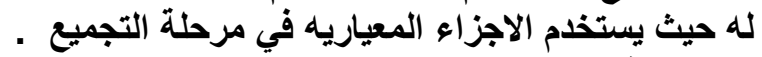

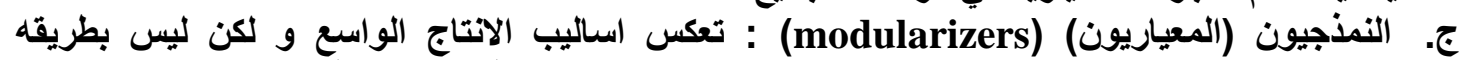

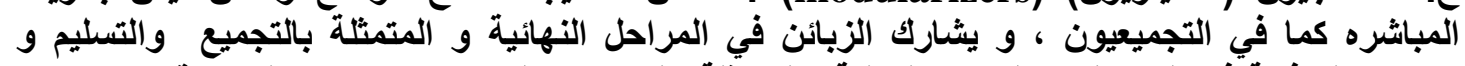

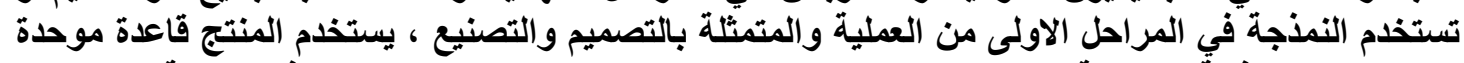

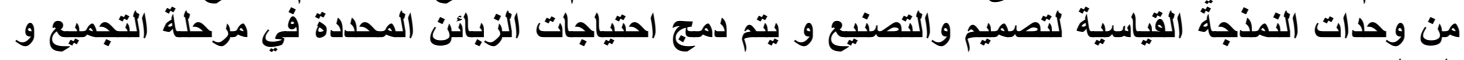

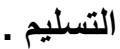

د. التجميعيون (assemblers) : في هذه الستراتيجية يكون مشاركة الزبون واستخدام النمذجة في

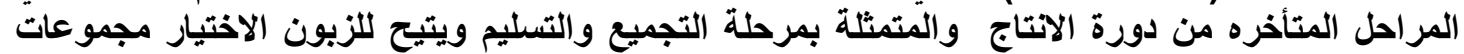

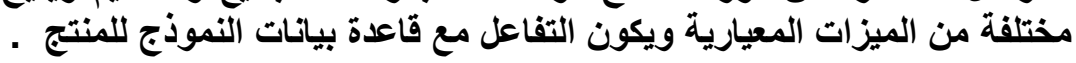




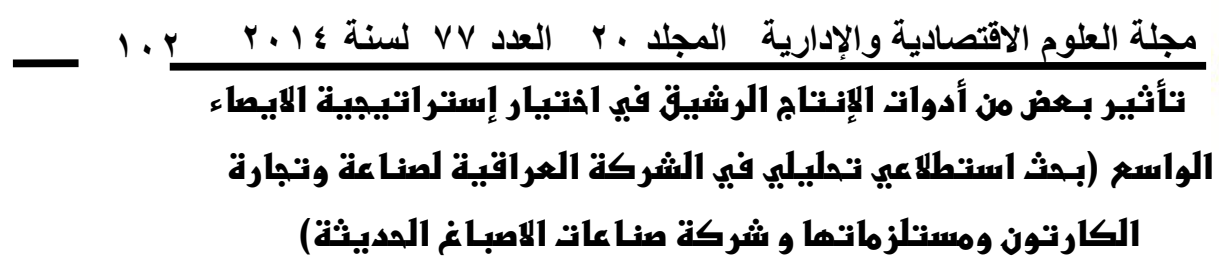

Duray et al. شكل (؛ ) يوضح مصفوفة تجميع من تكوينات الايصاء الواسع ل) 2000)

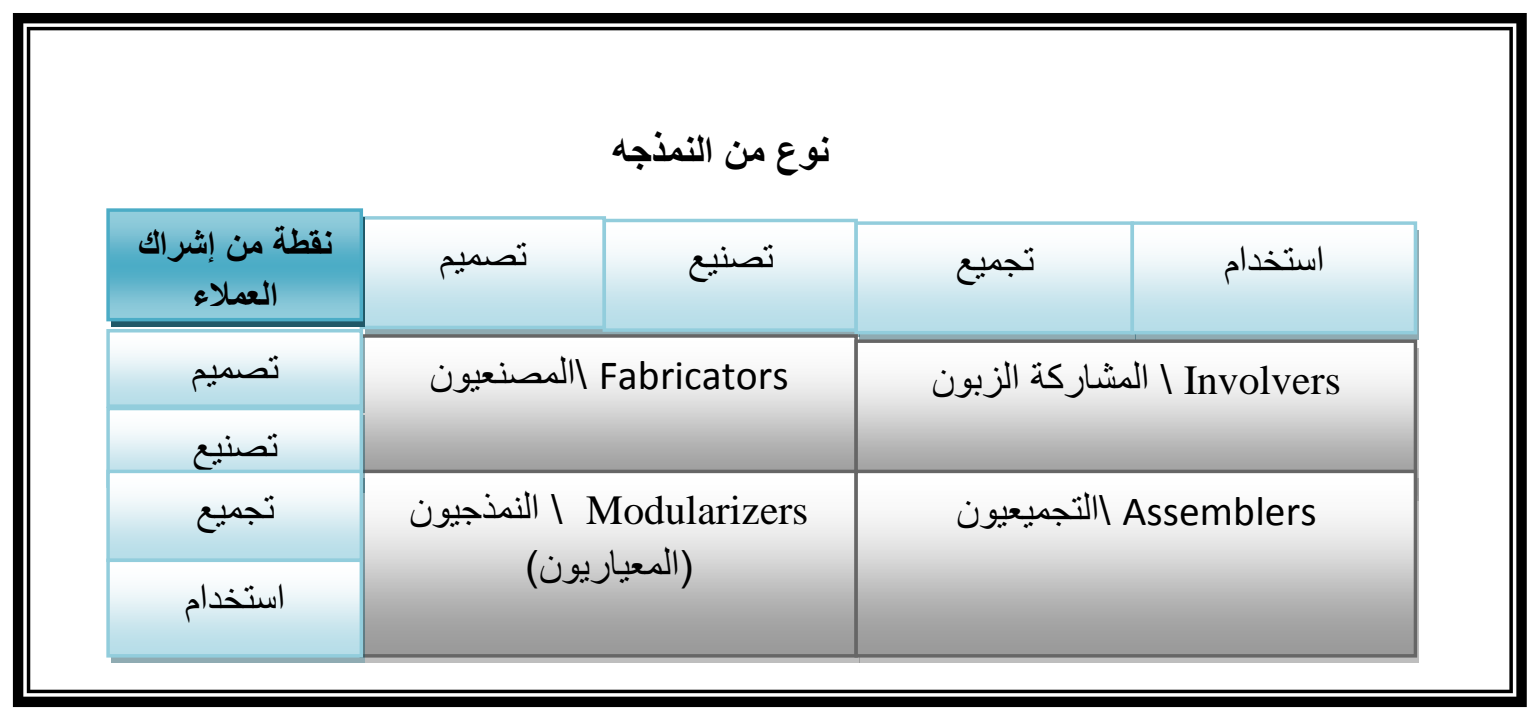

Source : NAHMENS, ISABELINA,2007, MASS CUSTOMIZATION STRATEGIES AND THEIR RELATIONSHIP TO LEAN PRODUCTION IN THE HOMEBUILDING INDUSTRY , P : 16

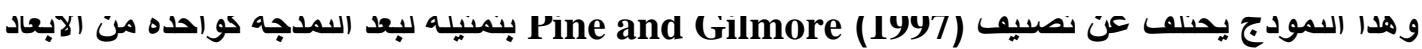

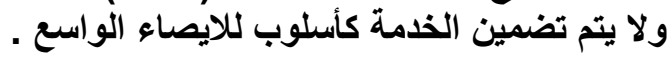

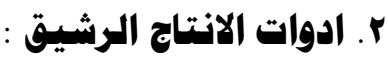

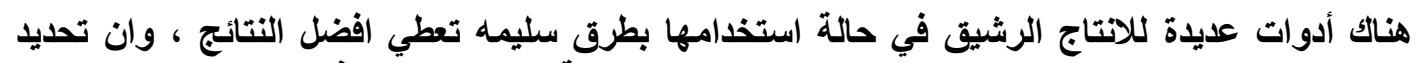

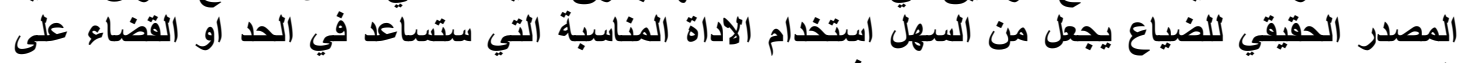

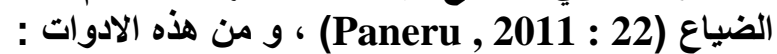

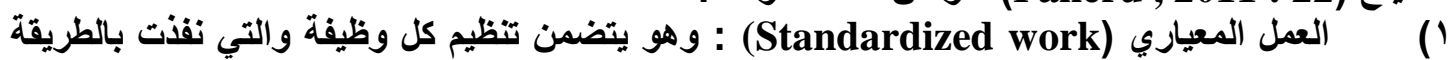

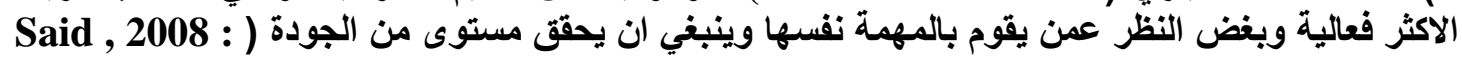

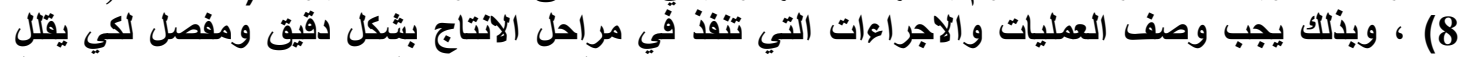

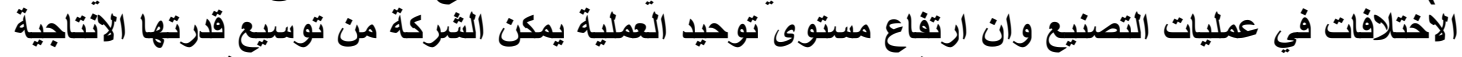

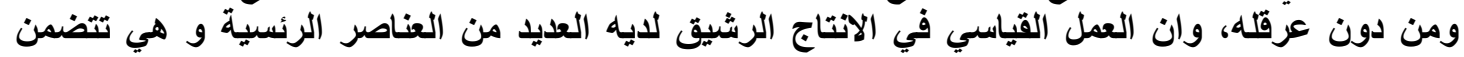

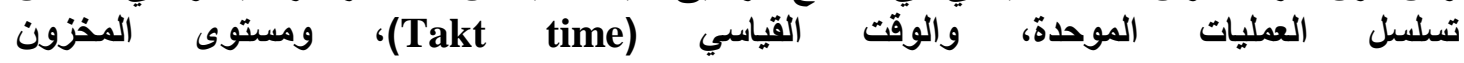

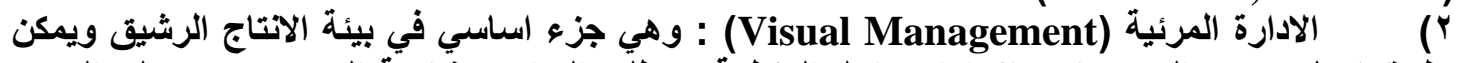

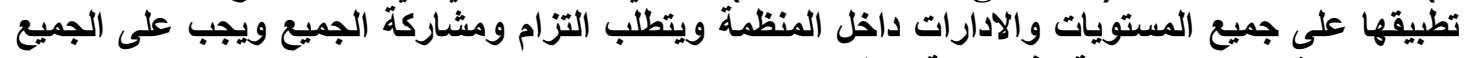

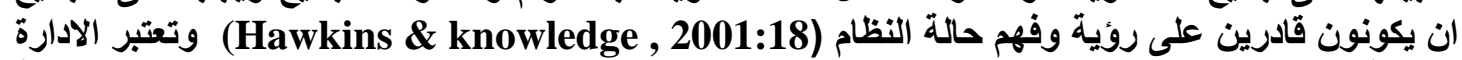

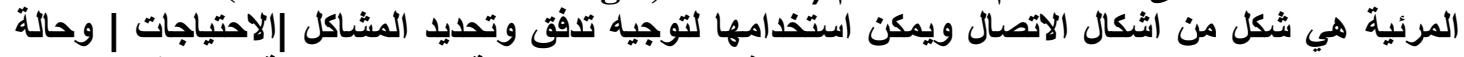

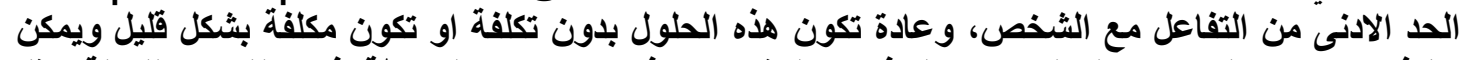

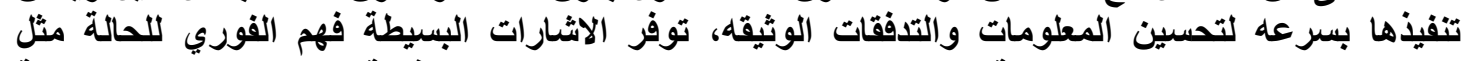

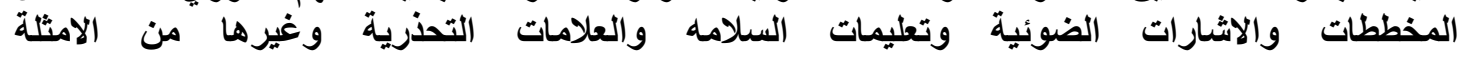

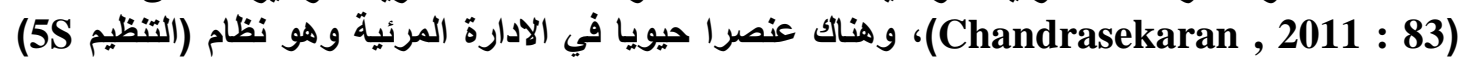
. (Goforth, $2007: 23$ )

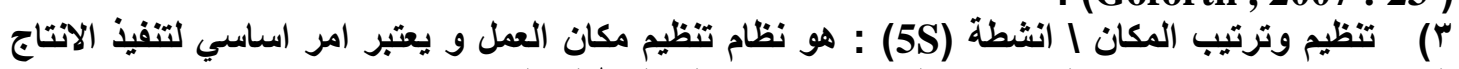

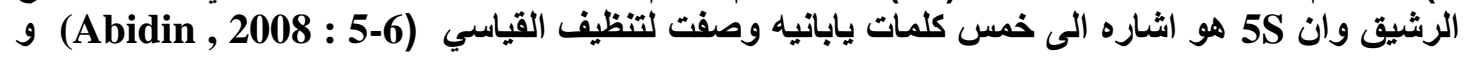




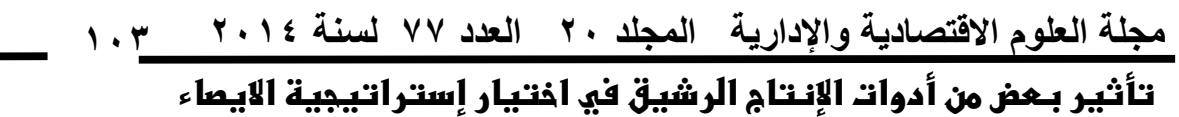

الواسع (بـث استطلاعي تمليلي في الشركة العراقية لصناعة وتنجارة

الكارتون ومستلزز ماتها و شركة صناعات الاصباغ العديثة)

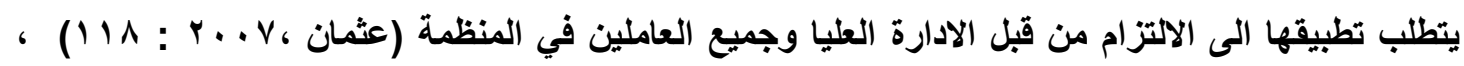

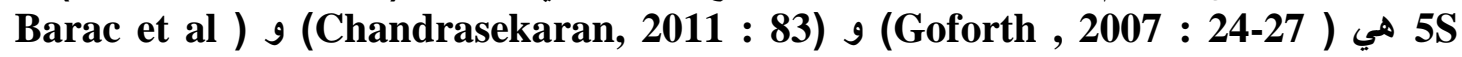
: (,2010: 329-330

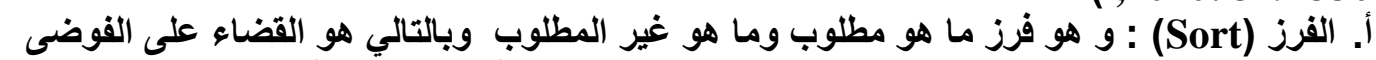

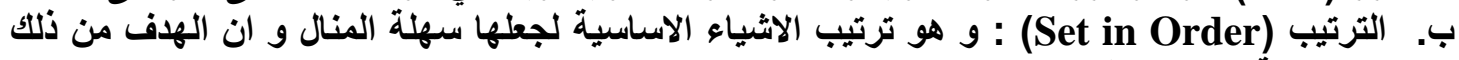
هو تقليل حركة العاملين اثناء اداء عملهم .

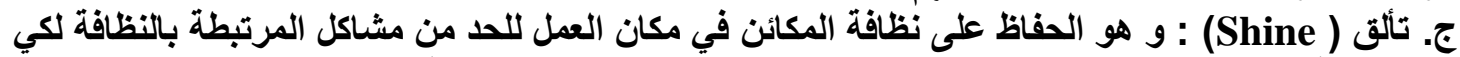

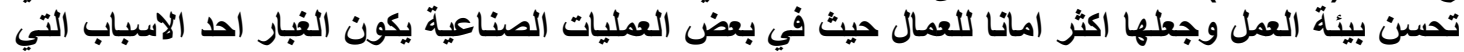

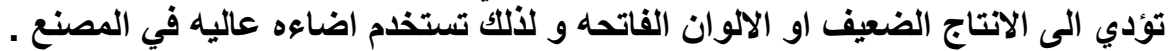

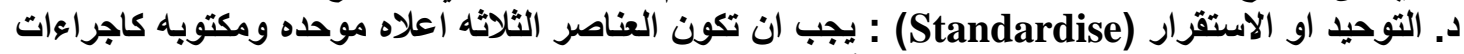

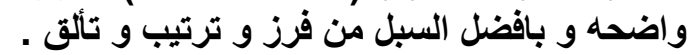

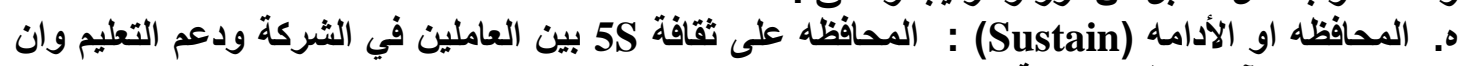
تصبح 5S جزعآ من نظام الثركة .

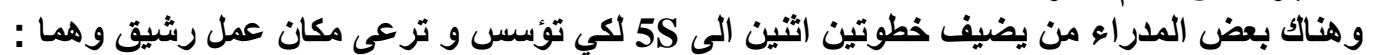

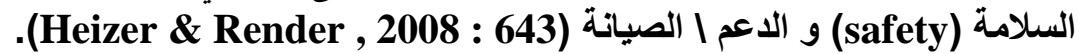

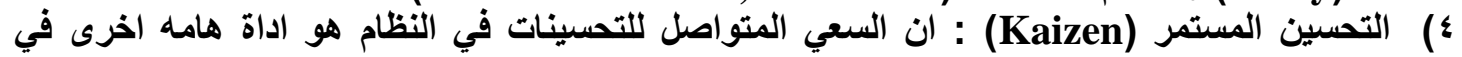

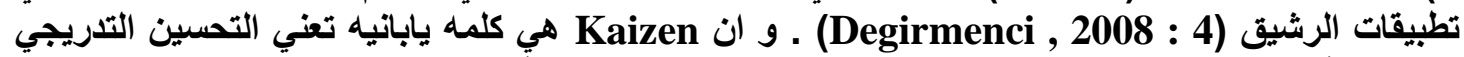

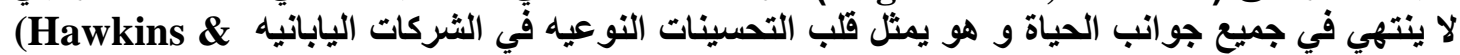

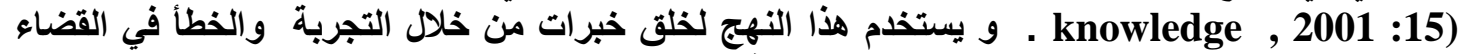

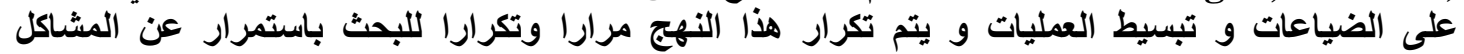

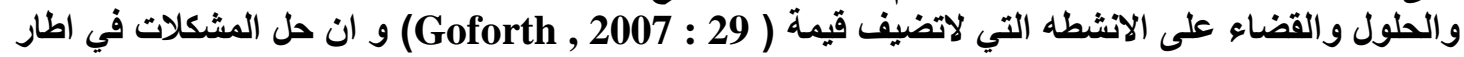
كايزن هو مدخل وظيفي و منهجي شُّامل و تعاوني (C4) : 1 :

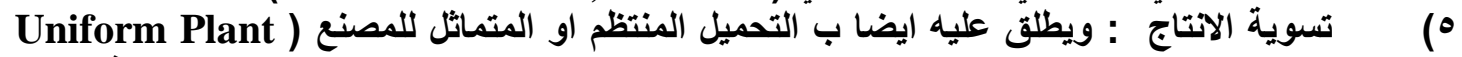

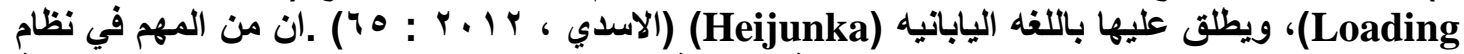

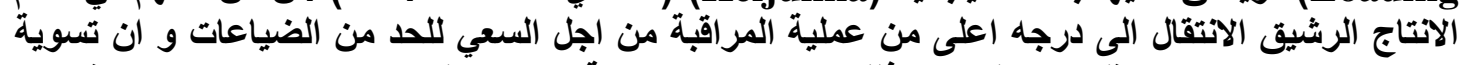

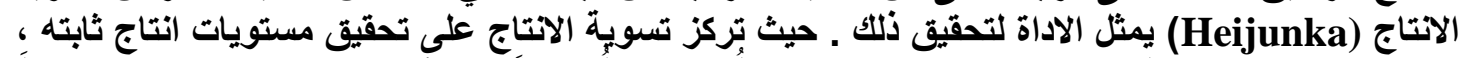

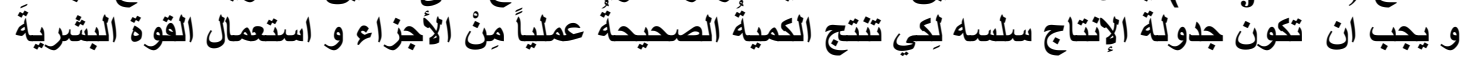

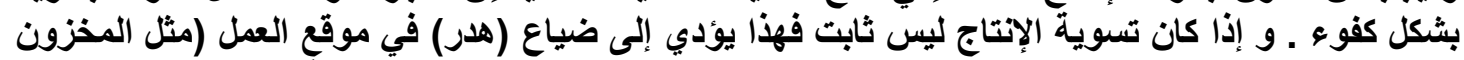

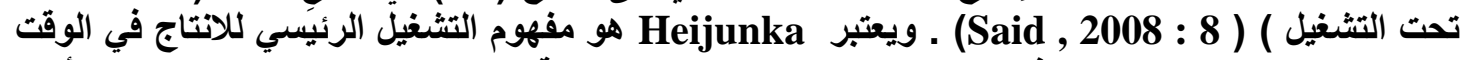

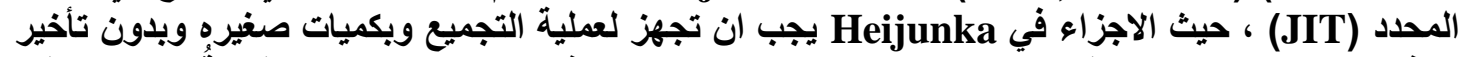

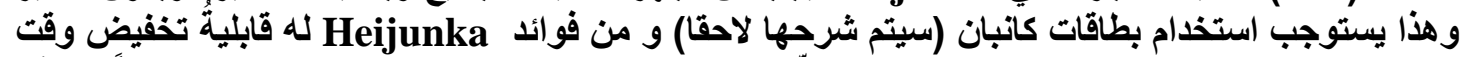

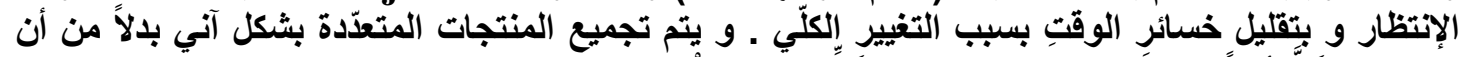

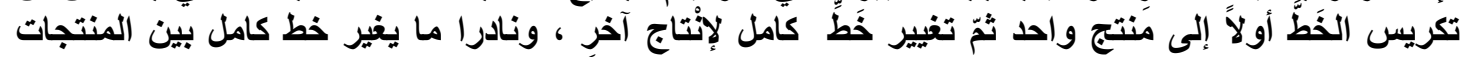

. ( Hawkins \& knowledge , 2001 : 12)

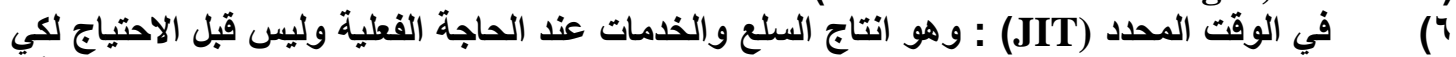

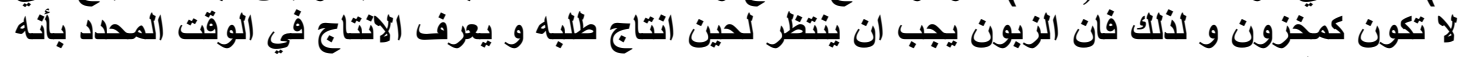

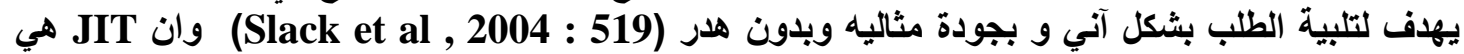

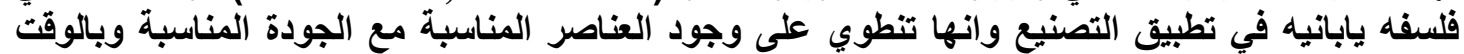

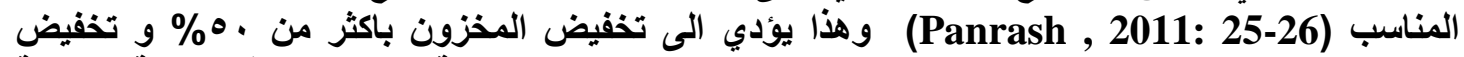

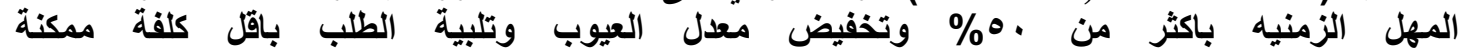

. (Chandrasekaran , 2011 : 83) 
و تستثد مبادئ JIT على استخدام الثائع لوصف مدخل تصنيع الانتاج قليل المخزون حيث يتم انتهاء

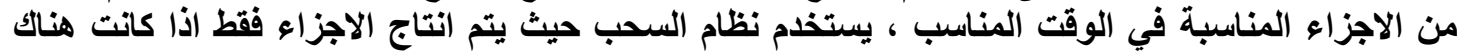

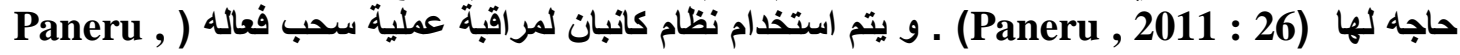
. (2011: 26

ويقصد بنظام كانبان (Kanban) و هو تطبيق في الانتاج الرشيق بأستخدام اوني التخزين وبطاقات

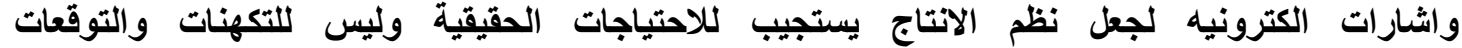

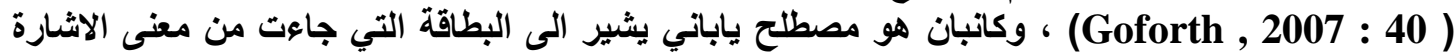

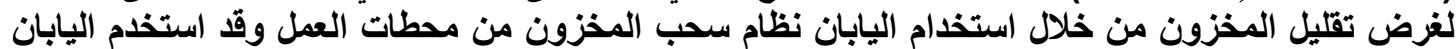

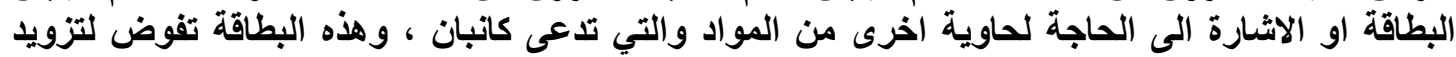

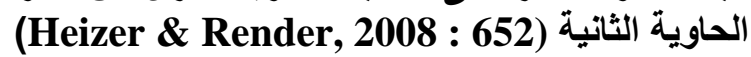

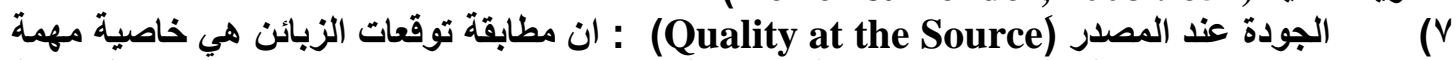

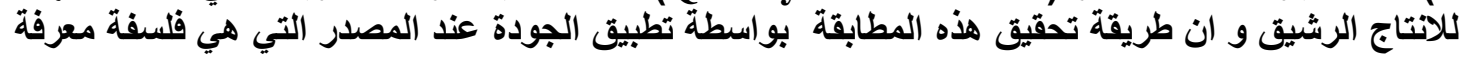

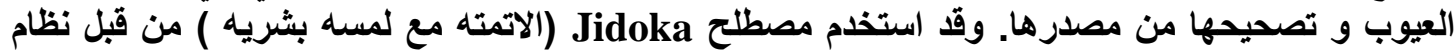

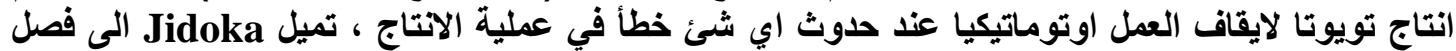

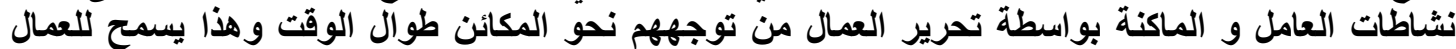

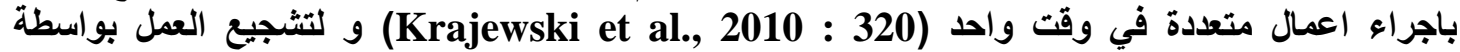
تتاح لكل عامل فرصة حصول على مفتاح تبديل التي يمكن استخدامها لتفعيل أضواء استداءع) (Jidoka)

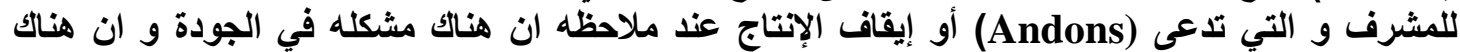
خمسة انواع مختلفة من الاضواء التي تعني مشاكل مختلفه وتستدعي المساعدة ) (

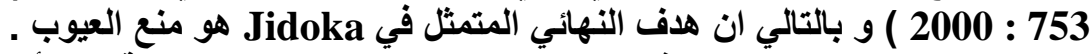

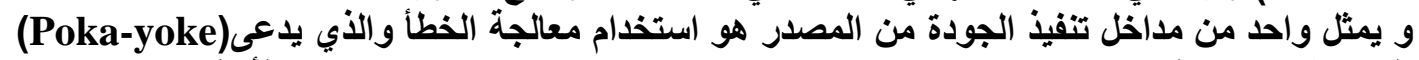

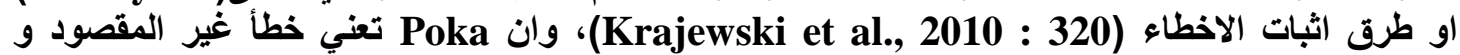

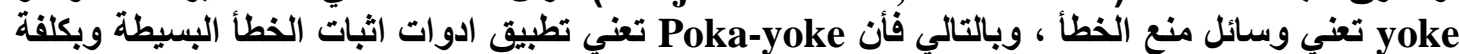

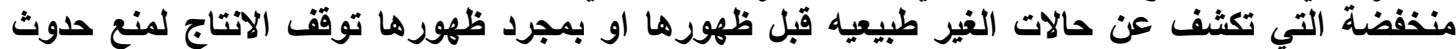

العيوب ، حيث تقدم Poka-yoke تغذية عكسية فوريه للاجراءات المضاده ( Goforth , 31 : 31 :

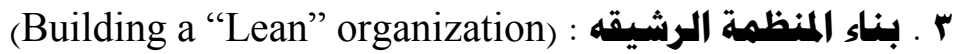

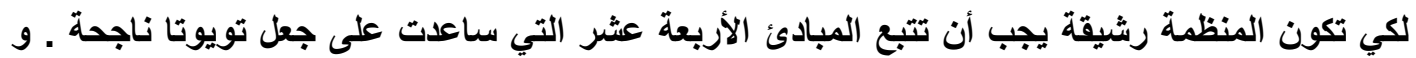

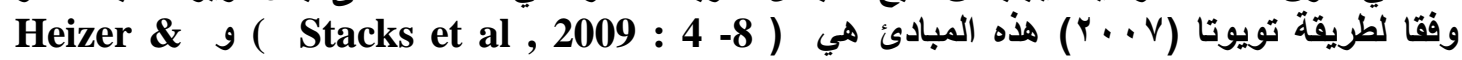
: ( Render , 2008) : 657 1. إسناد قرارات الإدارة الخاصة بالمنظمة على فلسفة طويلة الأجل ، حتى ولو كاتت على حساب أهداف

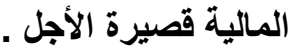

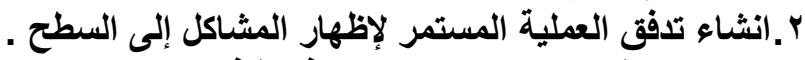

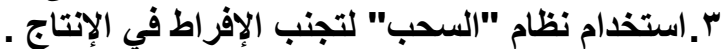

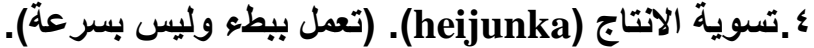

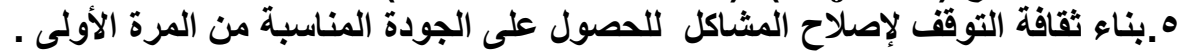

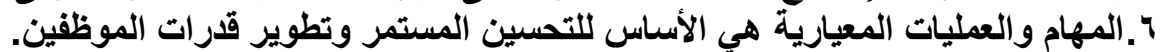

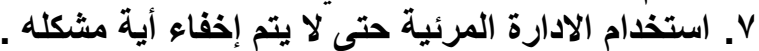

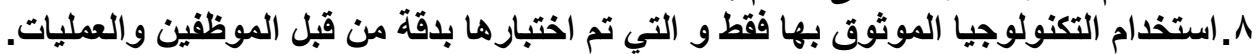

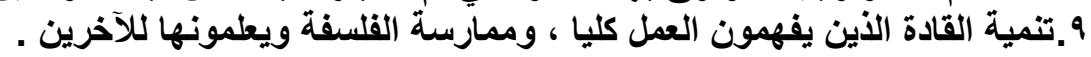

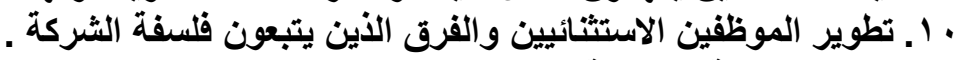

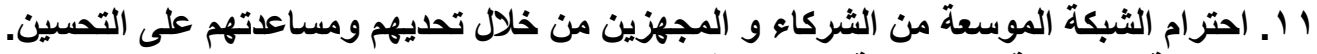

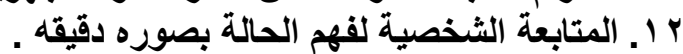

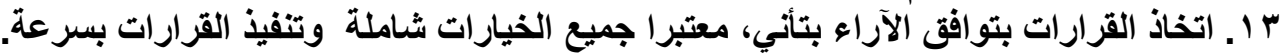
؛ ا ـ تصبح المنظمة متعلمة من خلال التفكير المستمر (hansei) والتئر التحسين المستمر (kaizen). 


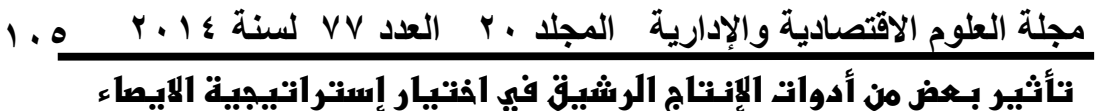

الواسع (بـث استطلاعي تصليلي في الشركة العراقية لصناعة وتنجارة

الكارتون ومستلزماتها و شركة صناعات الاصباغ الصديثة)

لقد بين (Liker 2004) ان هذه المبادئ تقود التقنيات والأدوات للانتاج الرشيق ، وقد قسمها الى أربعة

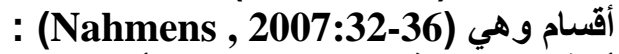

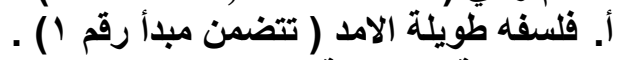

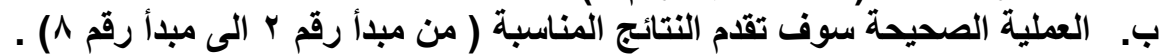

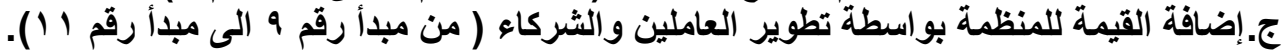

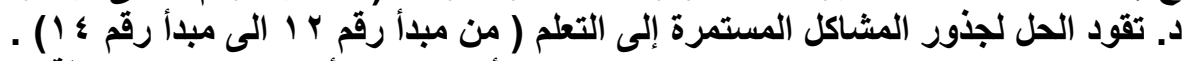

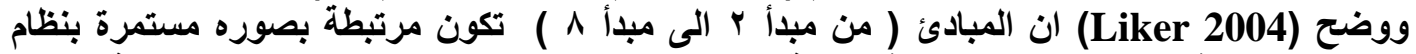

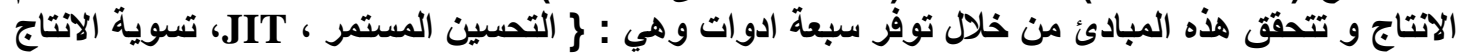

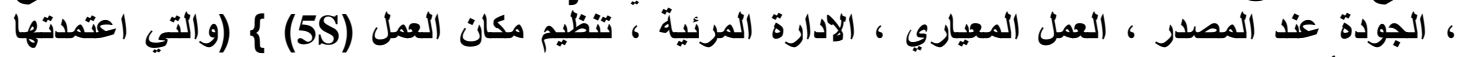

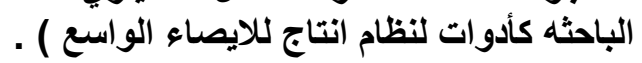

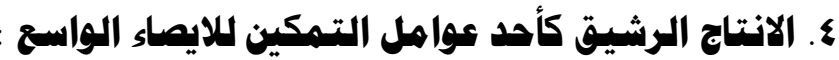

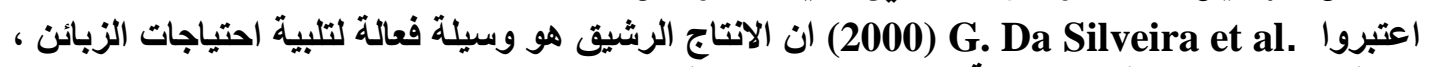

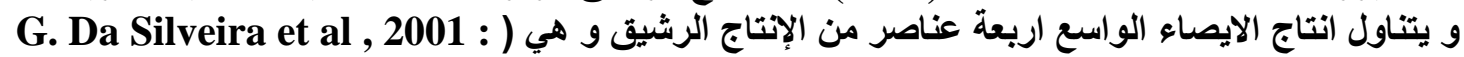
: $(6$

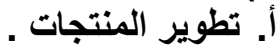

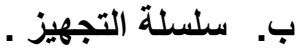

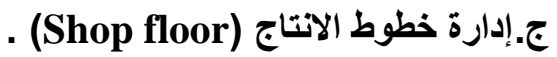

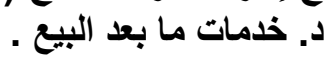

G. Da Silveira et al , و لنجاح تنفيذ نظام الايصاء الواسع من الضروري الأخذ بنظر الاعتبار ما يلي : (2001:) 6 تحديد القيمة على أساس الزبائن .

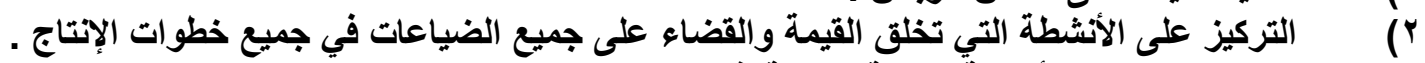

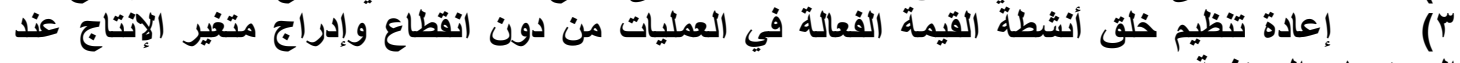

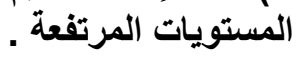

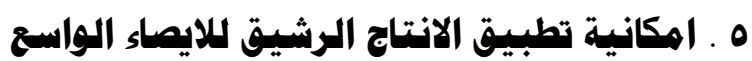

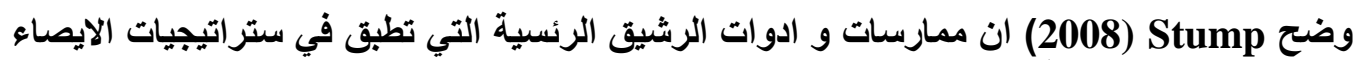

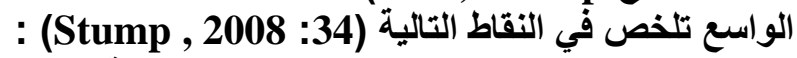

( ) يمكن الاستفاده من اداة الادارة المرائية و

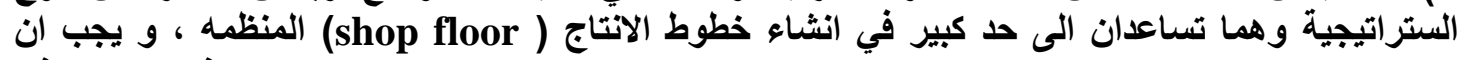

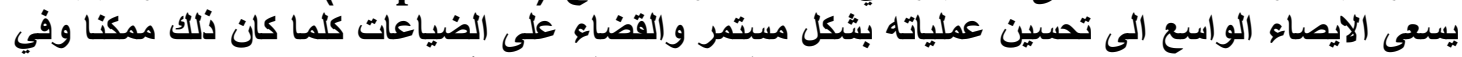

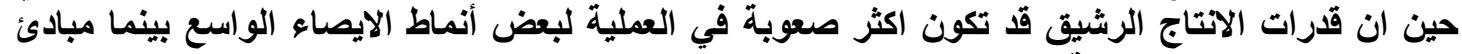

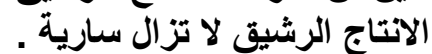

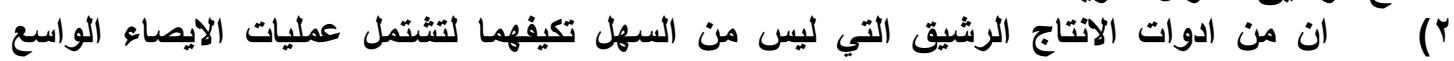

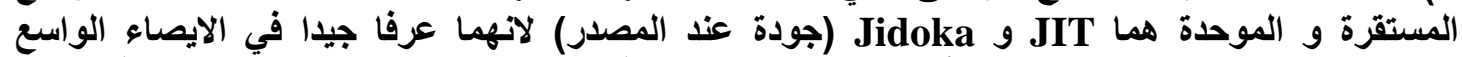

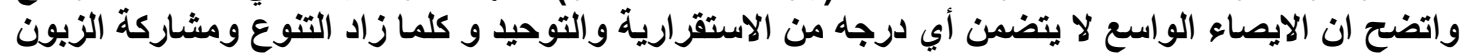

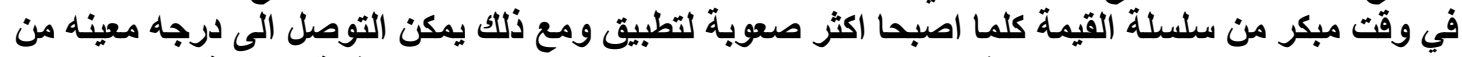

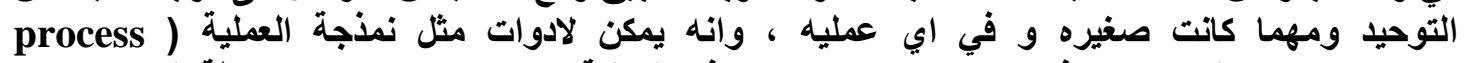
(modularity 


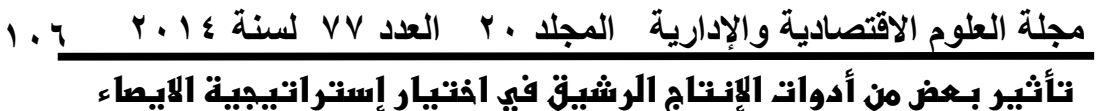

الواسع (بـث استطلاعي تحليلي في الشركة العراقية لصناعة وتنجارة

الكارتون ومستلزماتها و شركة صناعات الاصباغ الصديثة)

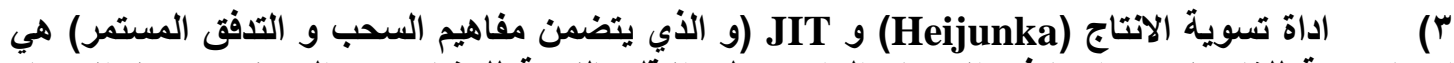

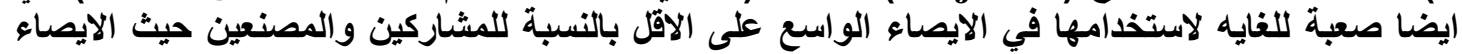

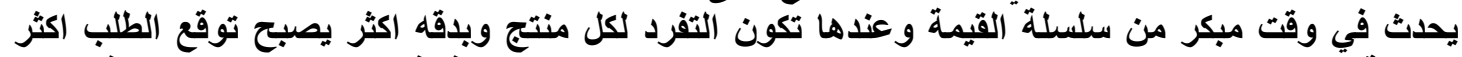

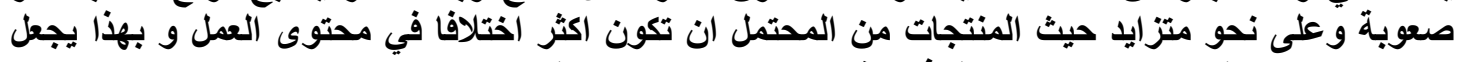

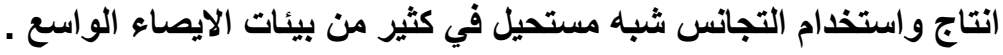

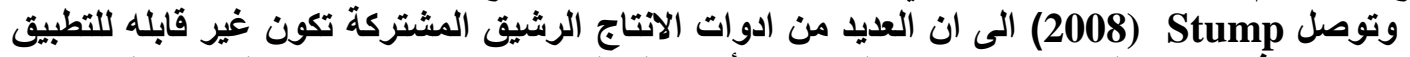

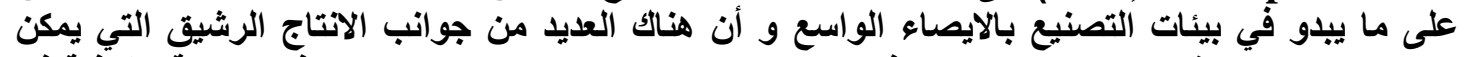

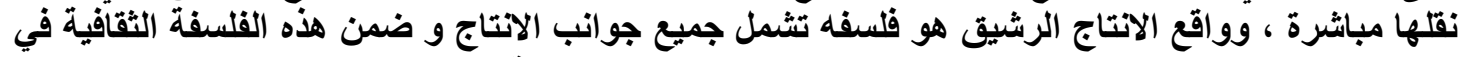

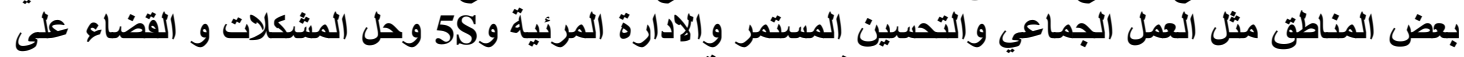

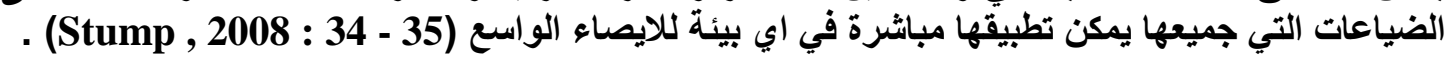

ثالثا : الجانب العهمبي

ا.اختبار فرضيات الفروق المعنوية لهينة البحث بين الشركتين حول المتغيرات :

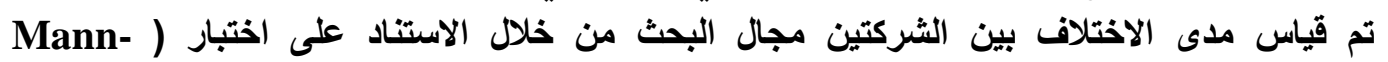
(Whitney

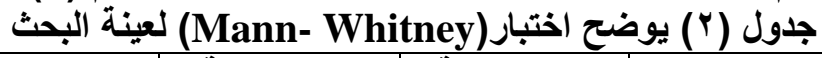

\begin{tabular}{|c|c|c|c|c|c|}
\hline الستراتيجية & التجنراتيجية & الستراتيجية & التعاونية التية & 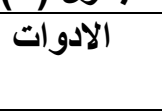 & \\
\hline 305.500 & 268.000 & 392.000 & 292.000 & 287.500 & $\begin{array}{c}\text { Mann- } \\
\text { Whitney U }\end{array}$ \\
\hline .119 & .031 & .866 & .076 & .067 & *مستوى المعنوية \\
\hline \multicolumn{6}{|c|}{ *مستوى المعنوية = 0.05 ، ذو اختبار( 2-tailed) من طرفين } \\
\hline
\end{tabular}

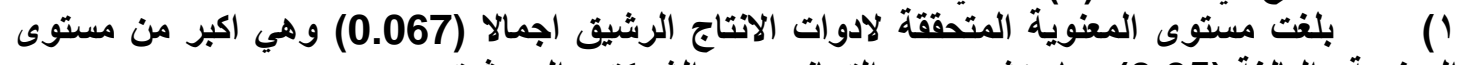

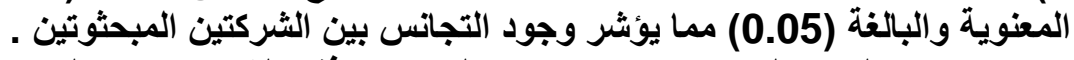

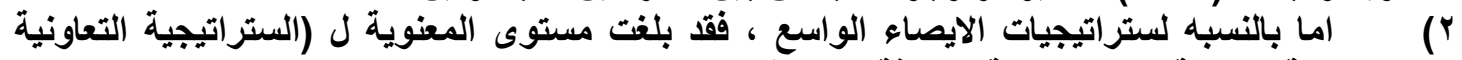

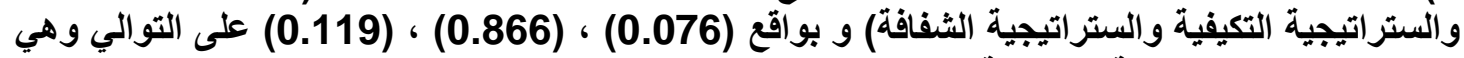

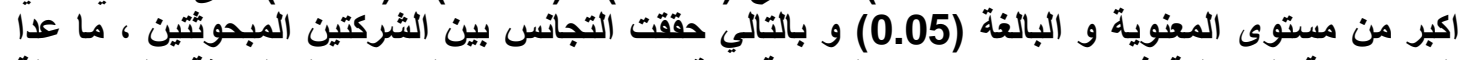

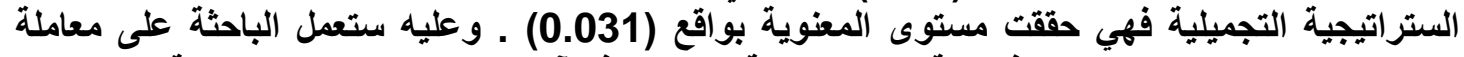

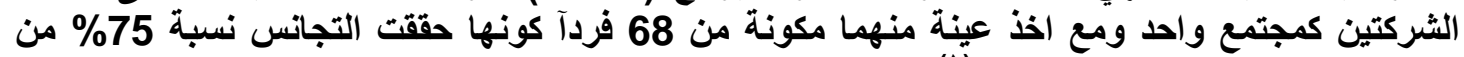

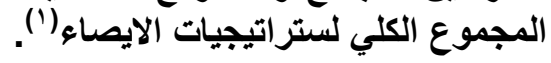

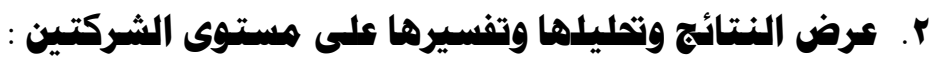

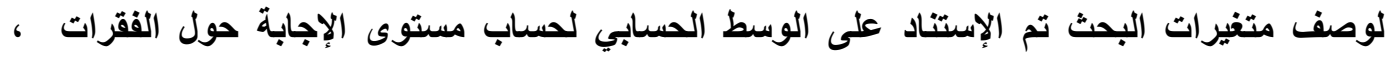

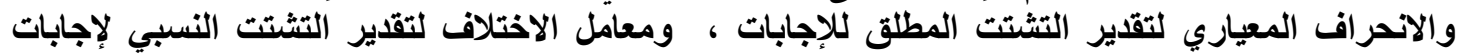

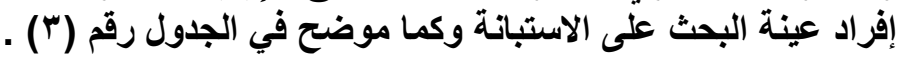




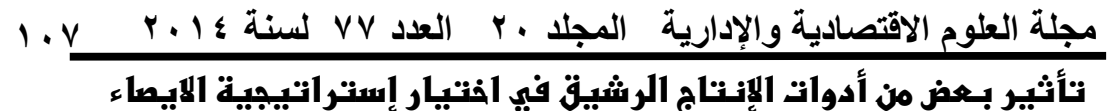

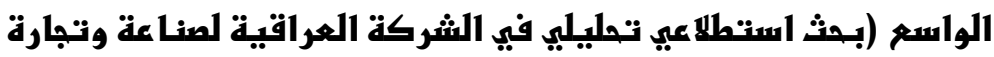

الكارتون ومس1تتلزماتها و شُركة صناعات الاصباغ الصدبثنة)

جدول (†r) يوضح الاوساط الحسابية و الانحرافات المعيارية و معامل الاختلاف لمتغيرات البحث الرئيسة والفرعية

\begin{tabular}{|c|c|c|c|}
\hline معامل الاختلاف & الانحراف المعياري & الوسط الحسابي & المتغيرات \\
\hline 17.09 & 0.70 & 4.12 & \multirow{8}{*}{ 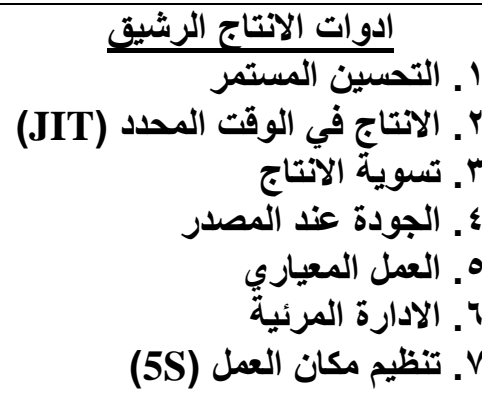 } \\
\hline 16.78 & 0.70 & 4.20 & \\
\hline 17.93 & 0.70 & 3.96 & \\
\hline 17.93 & 0.72 & 4.05 & \\
\hline 16.72 & 0.68 & 4.12 & \\
\hline 17.56 & 0.72 & 4.11 & \\
\hline 15.86 & 0.66 & 4.16 & \\
\hline 16.83 & 0.70 & 4.23 & \\
\hline 18.28 & 0.72 & 3.99 & \multirow{5}{*}{ 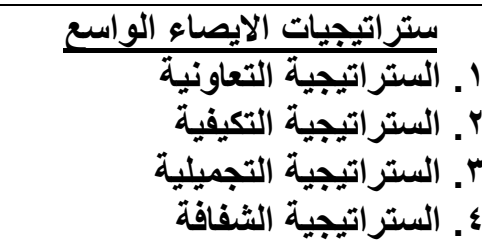 } \\
\hline 16.84 & 0.68 & 4.15 & \\
\hline 21.16 & 0.79 & 3.78 & \\
\hline 16.93 & 0.69 & 4.09 & \\
\hline 18.18 & 0.71 & 3.94 & \\
\hline
\end{tabular}

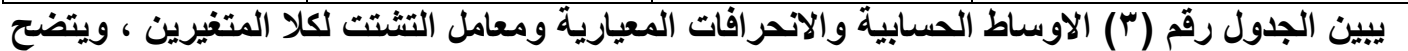

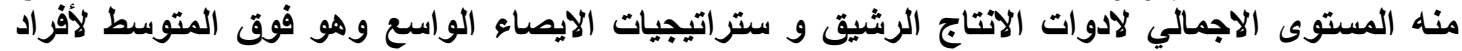

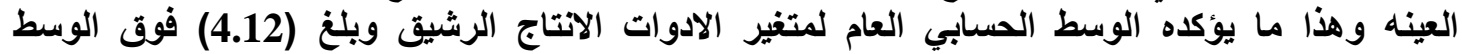

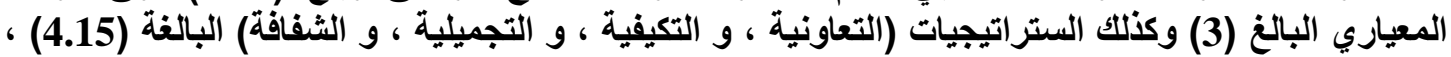

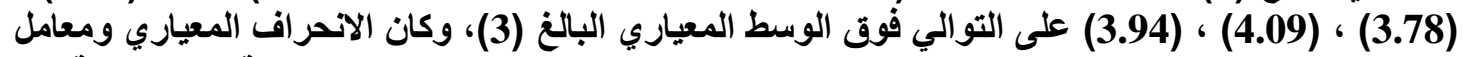

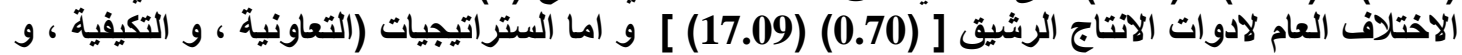

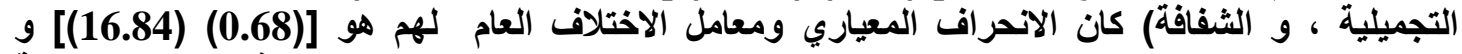

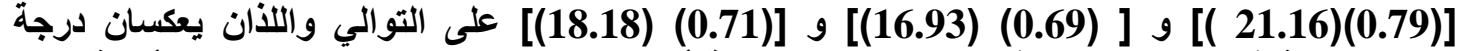
انسجام العينة في الإجابات ، وهذا يؤكد استخدام واهمية أدوات الإنتاج الرشيق والستراتيجيات الأربعة لعينه البحث.

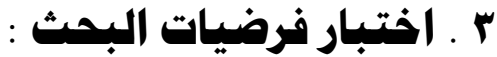

وضع البحث ثمانية فرضيات والتي تتعلق بالمتغير المستقل (ادوات الانتاج الرشيق) والمتفير التابع التابع

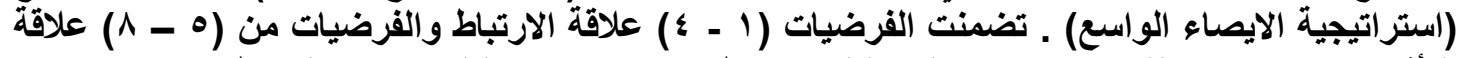

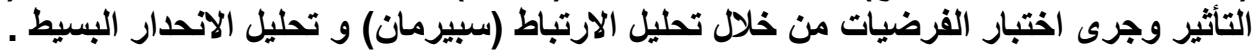

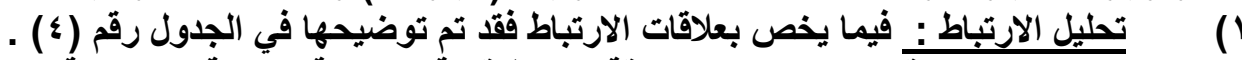

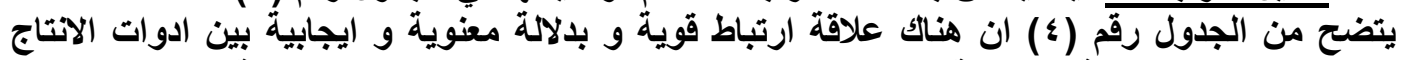

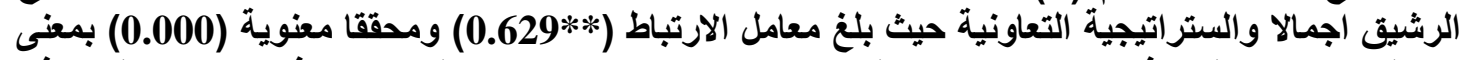

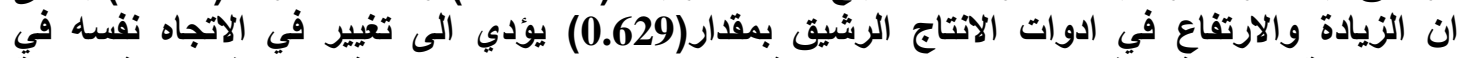

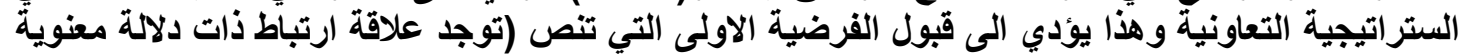
بين ادوات الانتاج الرشيق و الستراتية التيجة التعاونية) . 


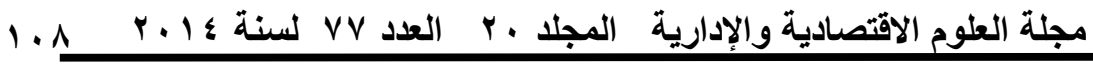

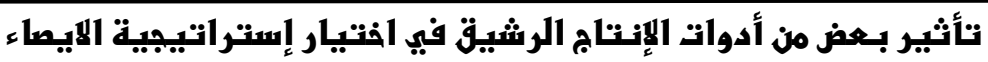

الواسع (بـث استطلاعب تصليلي في الشركة العراقية لصناعة وتنجارة

الكارتون ومستنلزماتها و شركة صنا عات الاصباغ العديثة)

جدول (؛) علاقات الارتباط بين ادوات الاتتاج الرشيق اجمالآ و استراتيجية الايصاء الواسع

\begin{tabular}{|c|c|c|c|c|c|}
\hline & ستراتيجية & ستر اتيجية & ستراتيجية & ستراتيجية & \multirow{3}{*}{ الأدوات } \\
\hline معامل الارتباط & $0.599 * *$ & $0.633 * *$ & $0.528 * *$ & $0.629 * *$ & \\
\hline المعنوية & 0.000 & 0.000 & 0.000 & 0.000 & \\
\hline
\end{tabular}

كنلك يتضح من الجدول اعلاه انه توجد علاقة ارتباط قوية و بدلالة معنوية و ايجابية بين ادوات التاتية

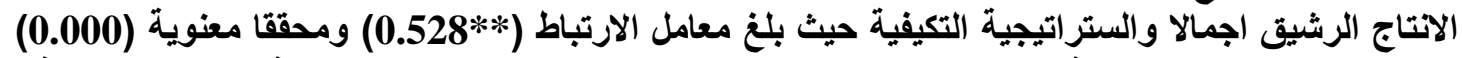

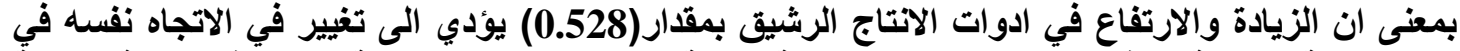

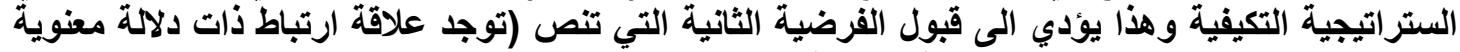
بين ادوات الانتاج الرشيق و الستراتيجية التئية التكيفية) .

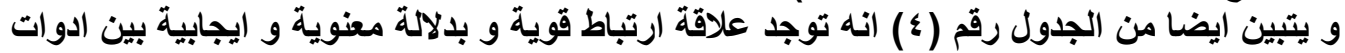

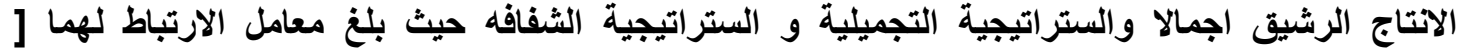

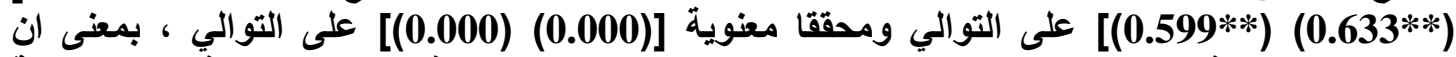

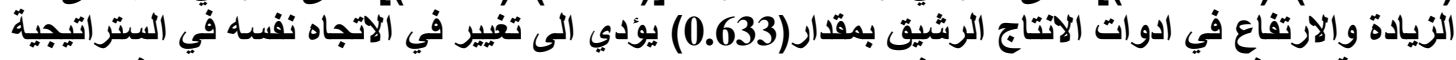

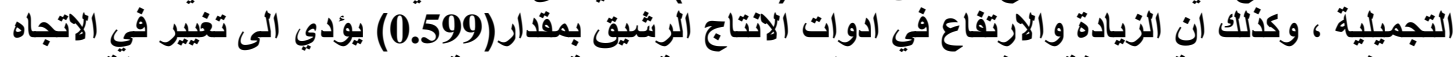

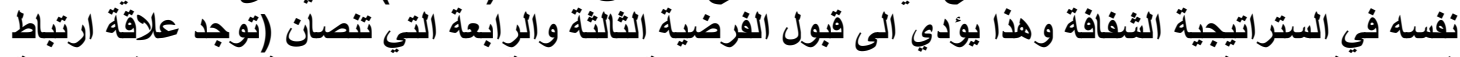

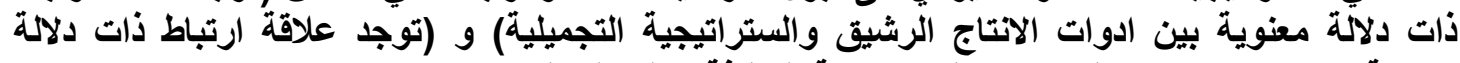

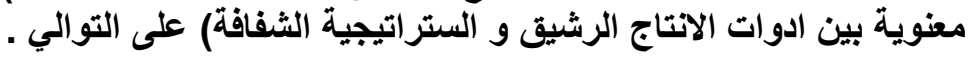

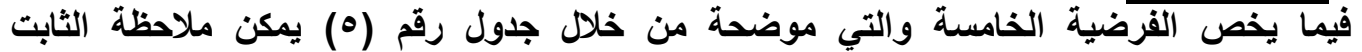

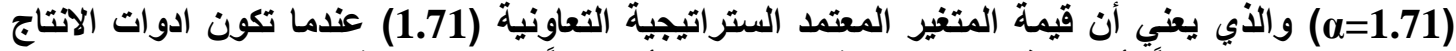

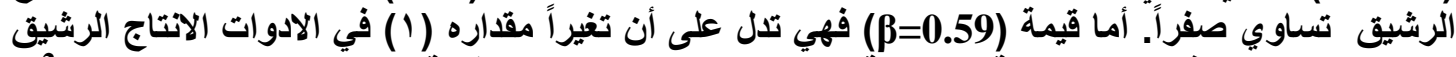

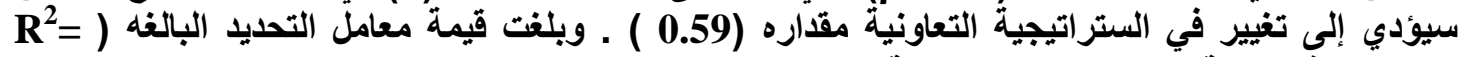

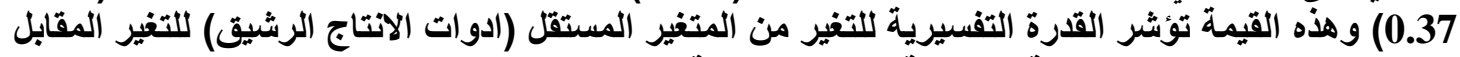

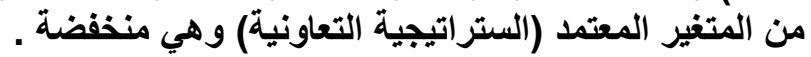

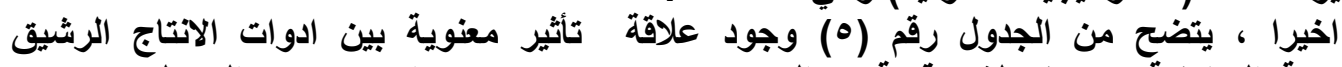

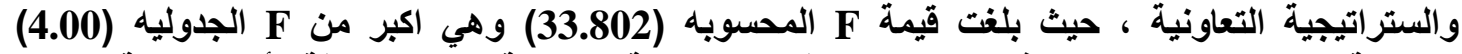
ومعنوية لمستوى (0.000) وهذه النتائج تؤكد قبول الفرضية التئة الخامسة (هناك علاقة تأثير معنوية لادوات الانتاج الرشيق على الستراتيجيةًأ التعاونية) .

جدول (0) علاقة التأثثر لادوات الانتاج الرشيق على الستراتيجية التعاونية

\begin{tabular}{|c|c|c|c|c|c|c|}
\hline $\mathbf{R}^{2}$ & df & $\boldsymbol{\beta}$ & $\alpha$ & المعنوية & F* المحسوبة F & المتغيرات \\
\hline 0.376 & $\begin{array}{l}1 \\
56 \text { (الانتحقار) } \\
56 \text { (المتبى) }\end{array}$ & 0.592 & 1.717 & 0.000 & 33.802 & والدوات الانتاجة الرشيقية التعاونية \\
\hline
\end{tabular}

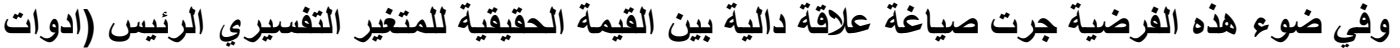
الانتاج ألرشيق) والمتغير الاستجابي الرئيس (الستراتيجية التعاونية) وكانت معادئة التئة الانحدار الخطي كالآتي: $Y=a+b X$ 


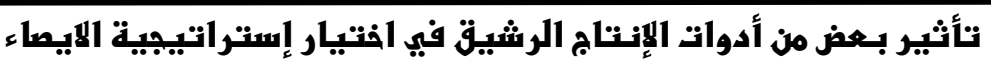

الواسع (بـث استطلاعي تصليلي في الشركة العراقية لصناعة وتنجارة

الكارتون ومستلزماتها و شركة صنا عات الاصباغ الصديثة)

الستراتيجية التعاونية = 1.717 + 1.592 (ادوات الانتاج الرشيق)

وبالتعويض في المعادله :

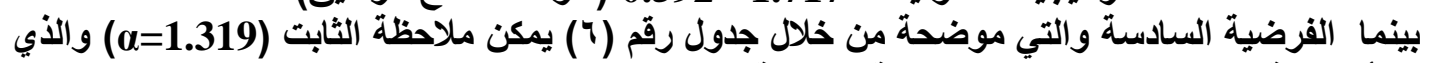

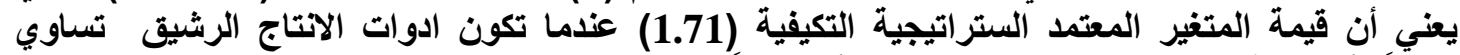

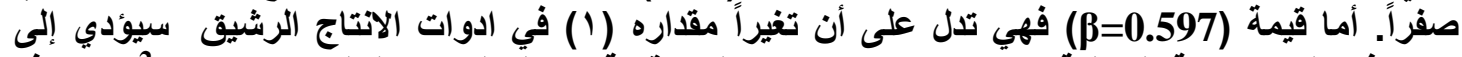

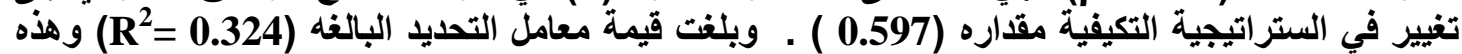
القيمة تؤشر القدرة التفيرية للتغير من المتغير المستقل (ادوات الانتاج الرشيق) للتغير المقابل من المتفير

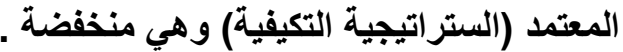

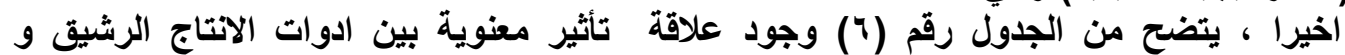

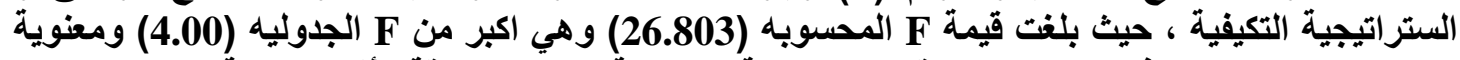

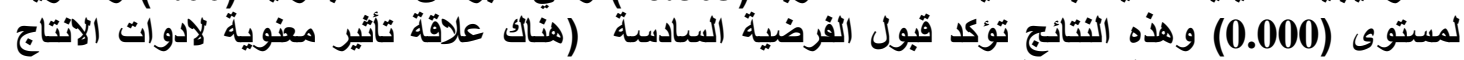
الرشيق على الستراتيجية التكيفية) .

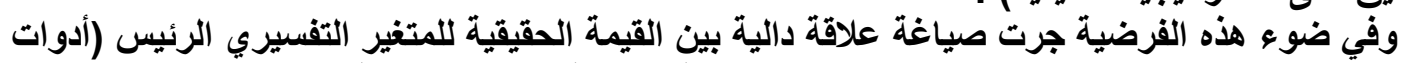

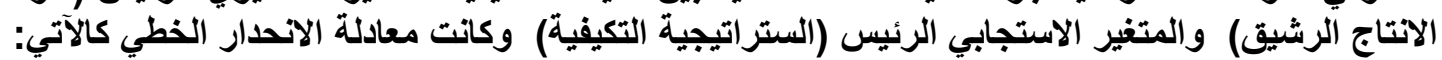

$$
\mathbf{Y}=\mathbf{a}+\mathbf{b X}
$$

الستراتيجية التكيفية = 1.319+1.597 (ادوات الانتاج الرشيق)

وبالتعويض في المعادله :

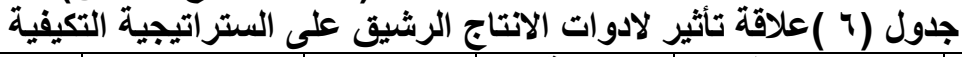

\begin{tabular}{|c|c|c|c|c|c|c|}
\hline $\mathbf{R}^{2}$ & df & $\beta$ & $\alpha$ & المعنوية * & F المحسوبة ** & المتغيرات \\
\hline 0.324 & 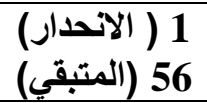 & 0.597 & 1.319 & 0.000 & 26.803 & الدوات الاتتاجة الرشيقية \\
\hline
\end{tabular}

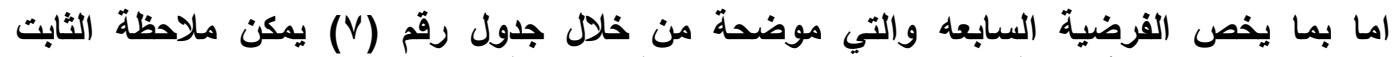

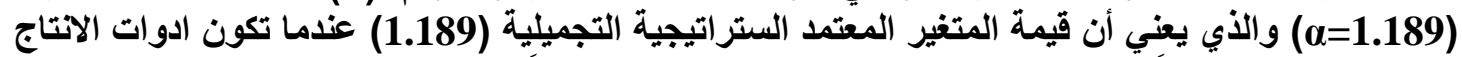

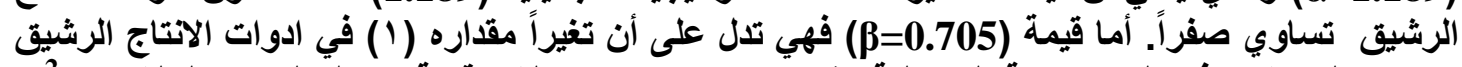

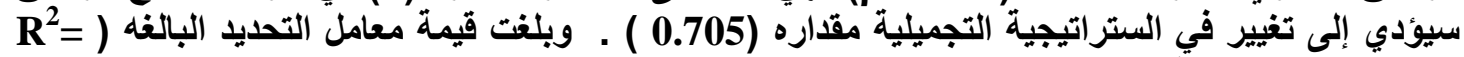

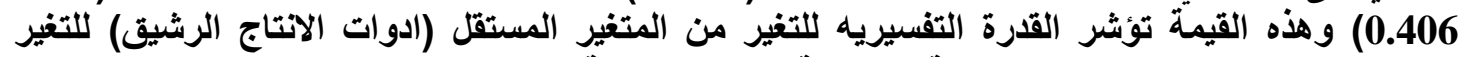

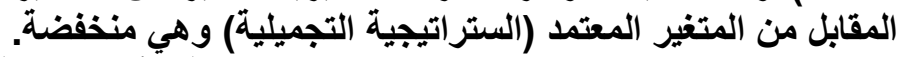

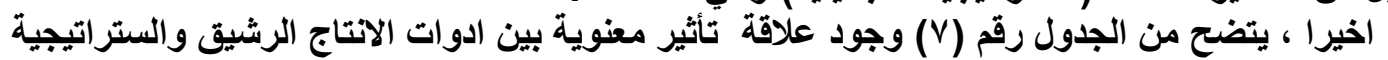

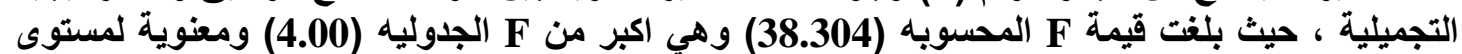

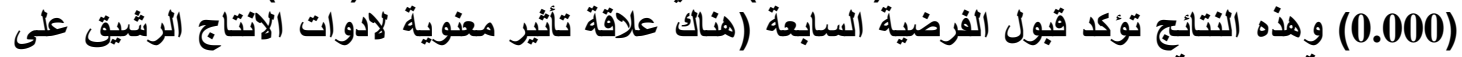

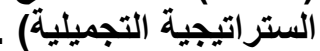
وفي ضوء هذه الفرضية جرت صياغة الإية علاقة دالية بين القيمة الحقيقية للمتغير التفسيري الرئيس (ادوات

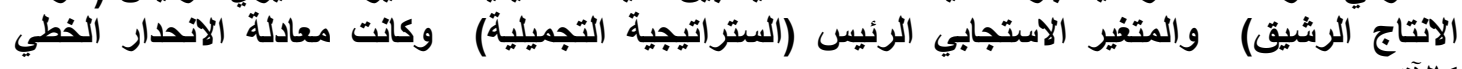

$$
\mathbf{Y}=\mathbf{a}+\mathbf{b X}
$$
كالآتي:

الستراتيجية التجميلية = 1.189 +0.705 (ادوات الاتتاج الرشيق) 


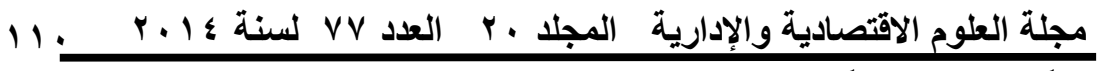

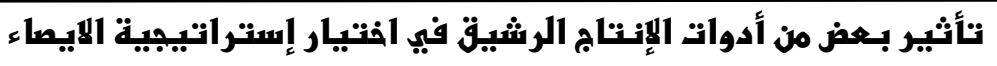

الواسع (بـث استطلاعي تصليلي في الشركة العراقية لصناعة وتنجارة

الكارتون ومستنلزماتها و شركة صنا عات الاصباغ العديثة)

جدول ( ) علاقات التأثير لادوات الاتتاج الرشيق على الستراتيجية التجميلية

\begin{tabular}{|c|c|c|c|c|c|c|}
\hline $\mathbf{R}^{2}$ & df & $\beta$ & $\alpha$ & المعنوية * & F المحسوبة ** & المتغيرات \\
\hline 0.406 & $\begin{array}{l}1 \\
56 \\
56\end{array}$ & 0.705 & 1.189 & 0.000 & 38.304 & والدتراتيجية التجميلية الرشيق \\
\hline \multicolumn{7}{|c|}{ 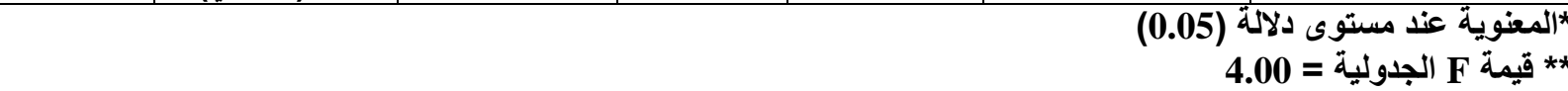 } \\
\hline
\end{tabular}

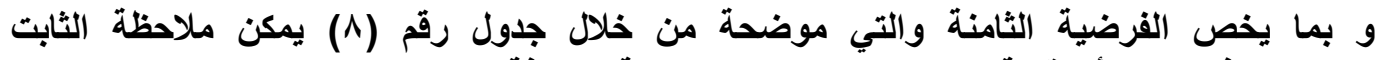

(a=0.855)

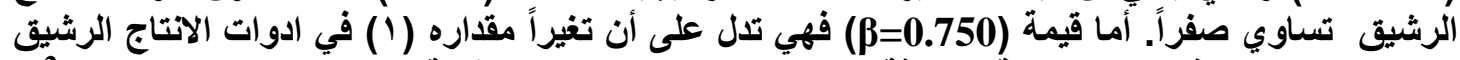

سيؤدي إلى تغيير في الستراتيجية الثنفافة مقاره (0.750).

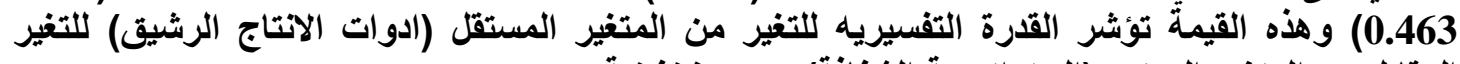

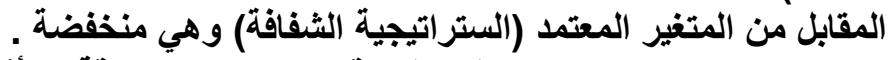

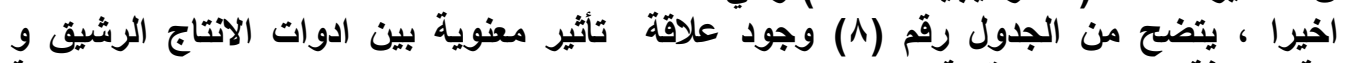

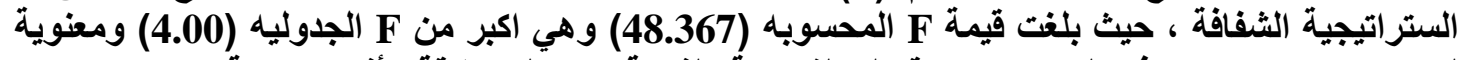

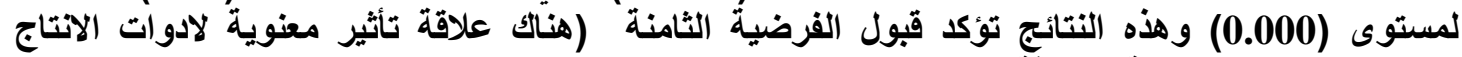

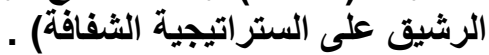

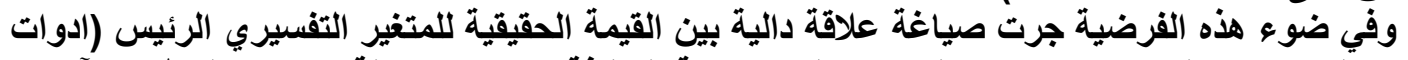

الانتاج الرشيق) والمتغير الاستجابي الرئيس (الستراتيجية الثفافة) وكانت معادلة الانحدار الغطي كالآتي:

$$
\mathbf{Y}=\mathbf{a}+\mathbf{b X}
$$

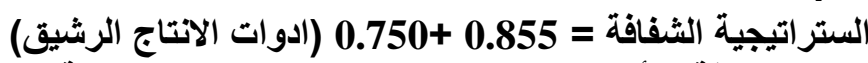

وبالتعويض في المعادله :

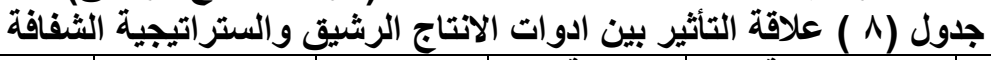

\begin{tabular}{|c|c|c|c|c|c|c|}
\hline $\mathbf{R}^{2}$ & df & $\beta$ & $\boldsymbol{\alpha}$ & المعنوية * & F المحسوبة * * & المتغيرات \\
\hline 0.463 & $\begin{array}{l}56 \text { ( الانحتبقار) } \\
56 \text { (المتب) }\end{array}$ & 0.750 & 0.855 & 0.000 & 48.367 & والستراتيجية الثيفافة التيقي \\
\hline
\end{tabular}

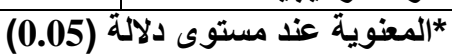

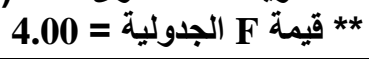

\section{ع . هلفص علاقات الارتباط والثأثير وترتيب الستراتيبيات حسب درجة اهميتها :}

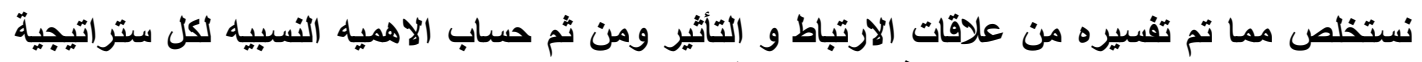

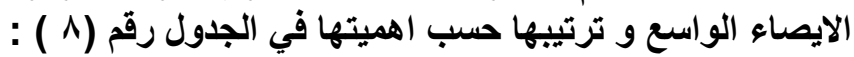

جدول ( ^) ملخص العلاقات بين المتغيرين وآلاهميه النسبيه لكل ستراتيجية الايصاء الواسع وترتيبها حسب الاهمية

\begin{tabular}{|c|c|c|c|c|c|}
\hline \multirow{5}{*}{ أدوات الانتاج الرشيق } & ستراتيجية & ستراتيجية & ستراتيجية & ستراتيجية & \\
\hline & 0.000 & 0.000 & 0.000 & 0.000 & معنوية الارتباط مع الأدوات \\
\hline & 0.000 & 0.000 & 0.000 & 0.000 & معنوية تأثرها بالأدوات \\
\hline & $78.8 \%$ & $81.8 \%$ & $75.6 \%$ & $83 \%$ & الأهمية النسبية لكل ستر اتيجية \\
\hline & 3 & 2 & 4 & 1 & ترتيب الستراتيجية حسب أهميتها \\
\hline
\end{tabular}

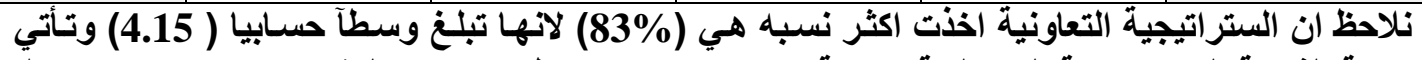

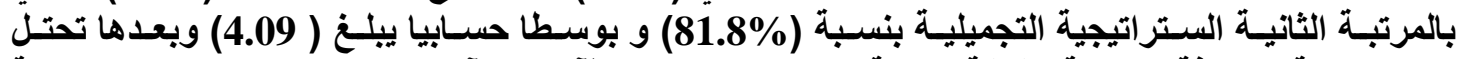

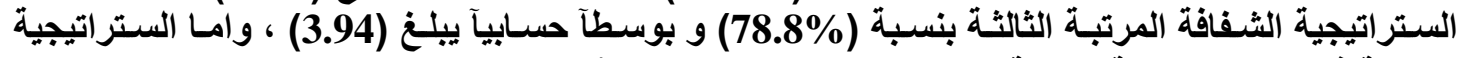

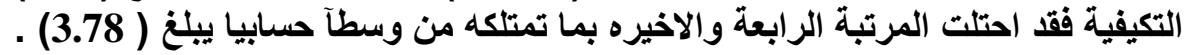

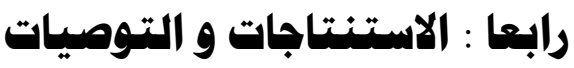

و ـ الاستنتاجات : يتضمن البحث مجموعة من الاستتتاجات التي تم التوصل إليها البحث بجانبه التطبيقي ، 


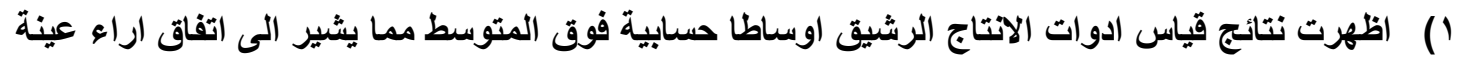

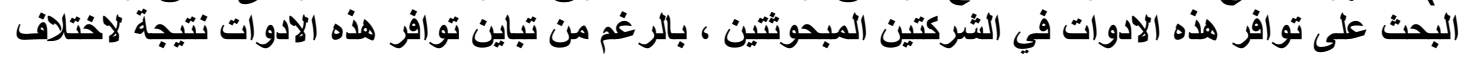

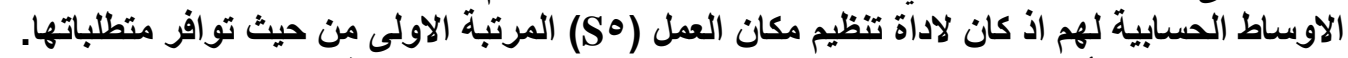

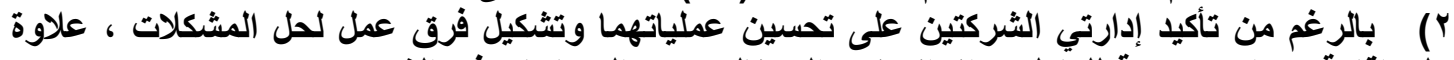

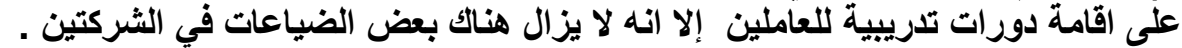

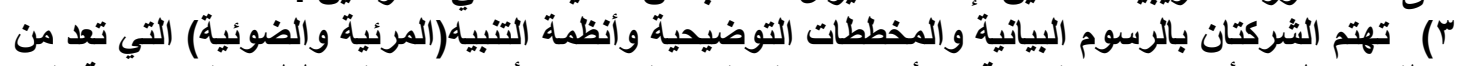

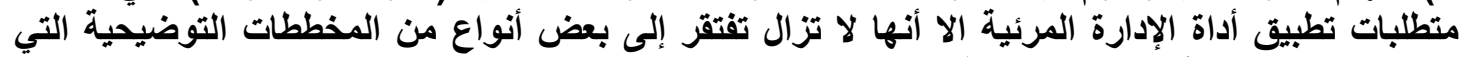

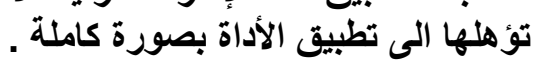

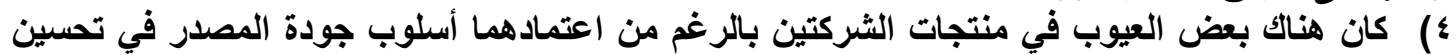

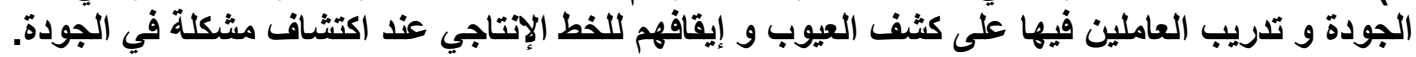

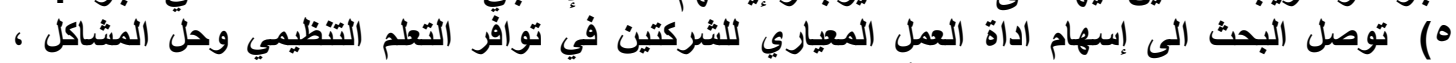

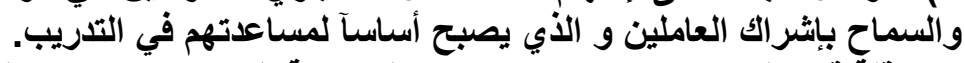

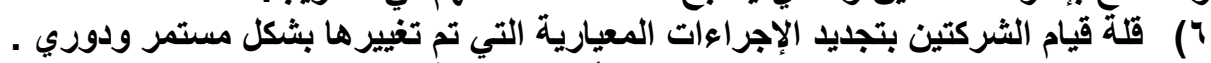

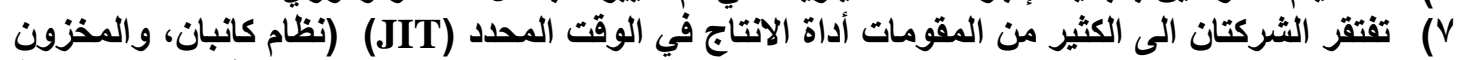

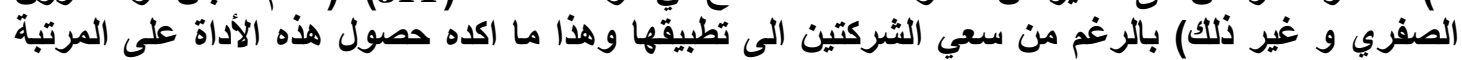

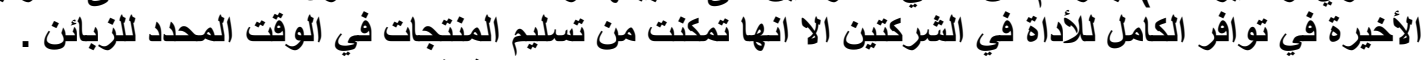

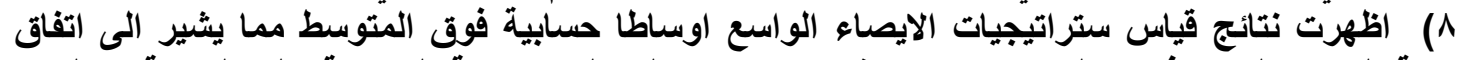

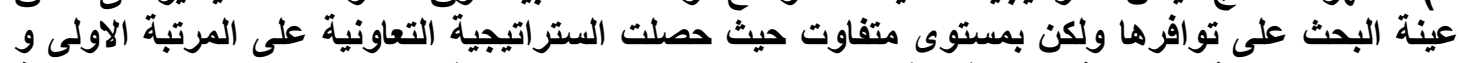

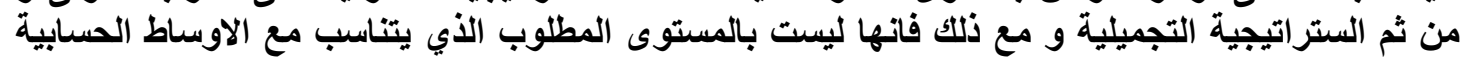

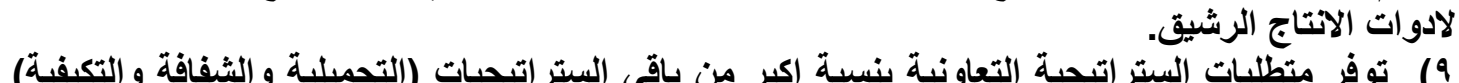

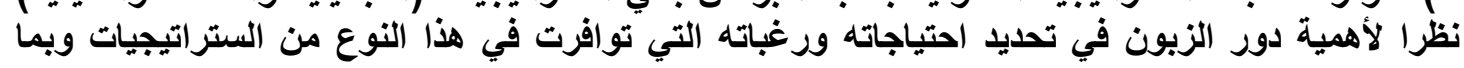

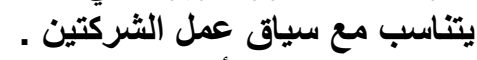

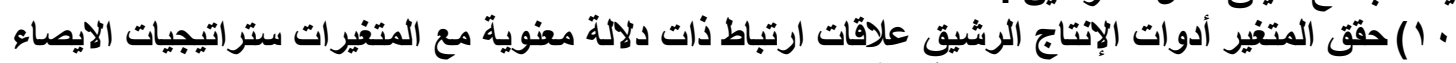

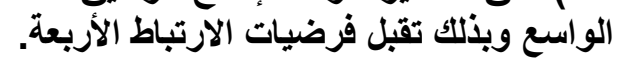

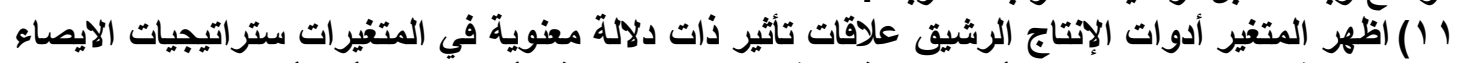

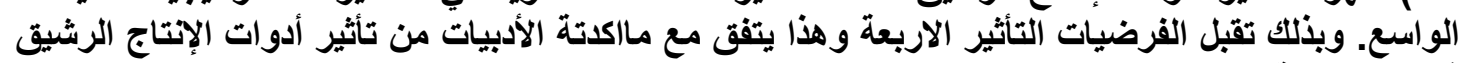

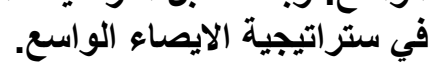
r. التوصيات : استكمالاً للمتطلبات المنهجية وتأسيساً على ما توصلت إليهاء اليها الباحثة من نتائج وما بني

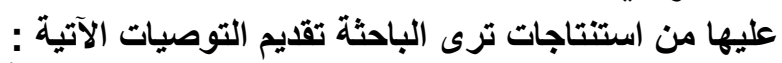

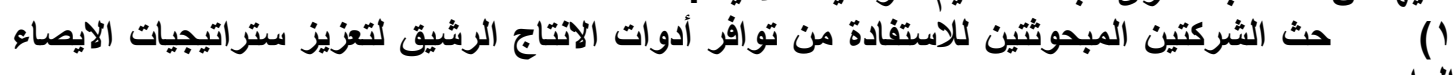

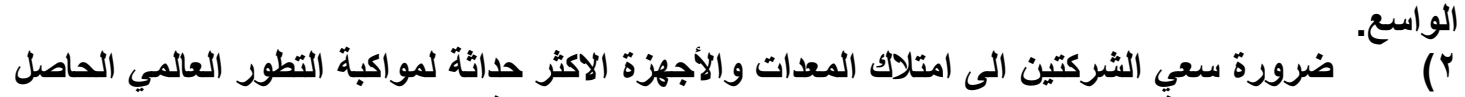

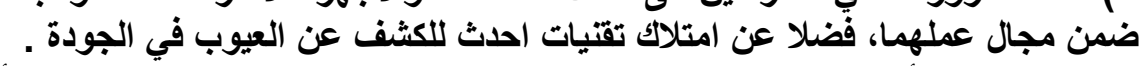

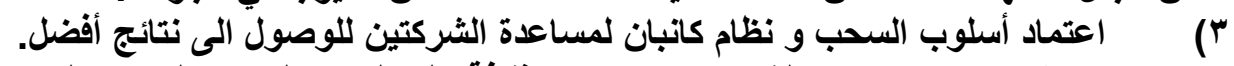

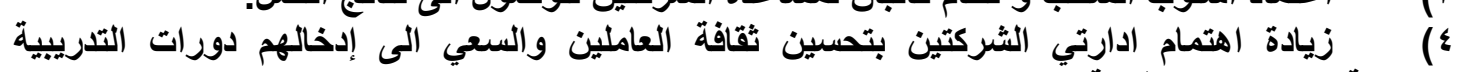

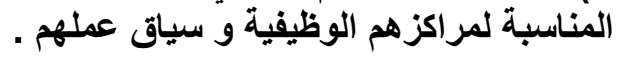




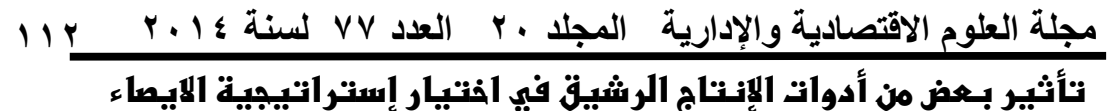

الواسعر (بـث استطلاعي تصليلي في الشركة العراقية لصناعة وتجارة

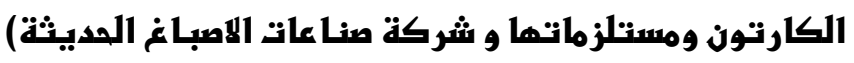

ه) زيادة اهتمام الثركتين بالتوعية لثقافة الضياعات الصفرية بين العاملين وبطرائق إزالة كل إثكال الضياعات.

") "تحتاج الثركتان استخدام المخططات البيانية لتحديد حدود السيطرة لكي تطبق أداة الجودة عند المصدر بصورة كاملة.

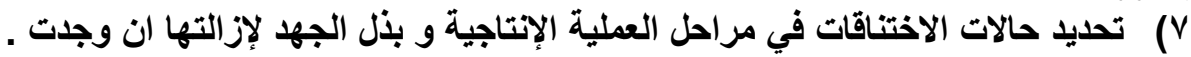

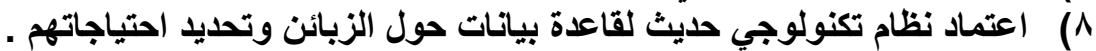

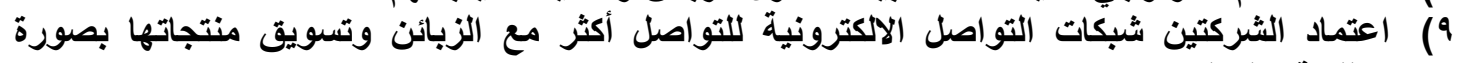

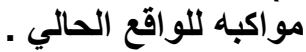

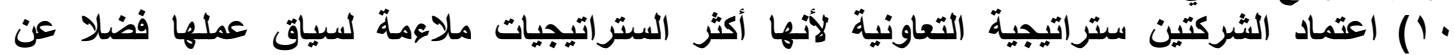

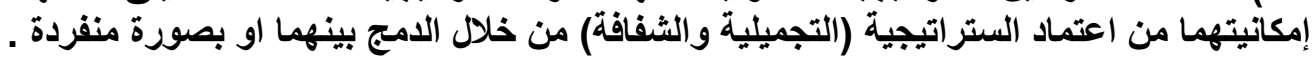

المادر :

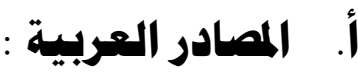

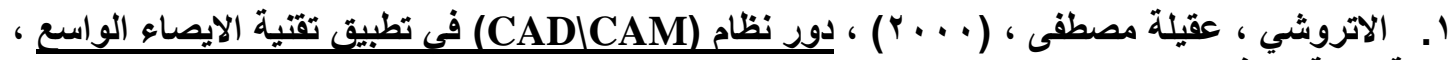

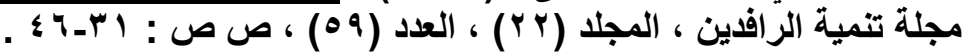

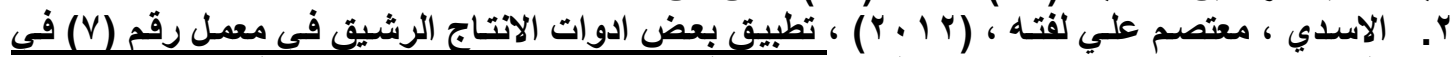

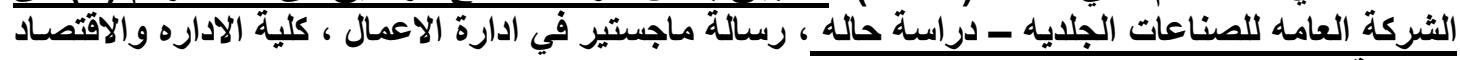

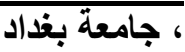

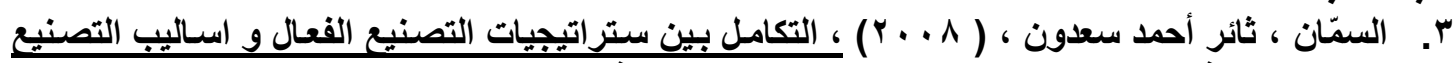

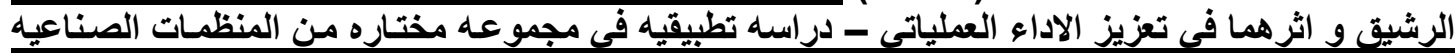

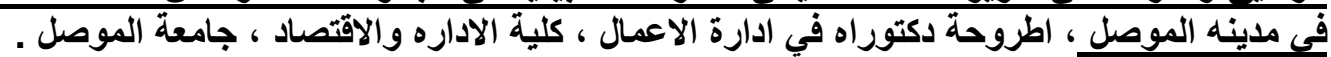

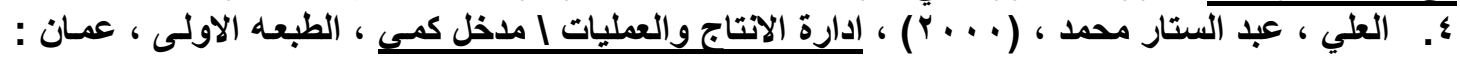

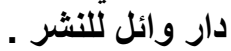

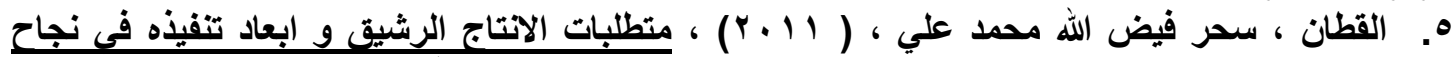

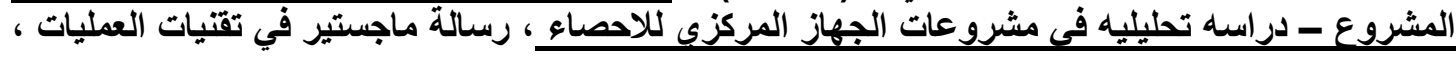

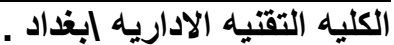

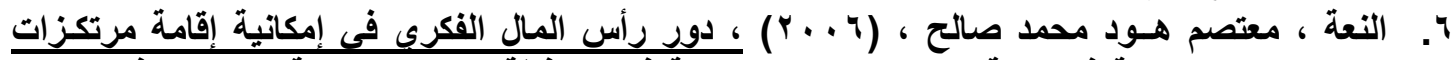

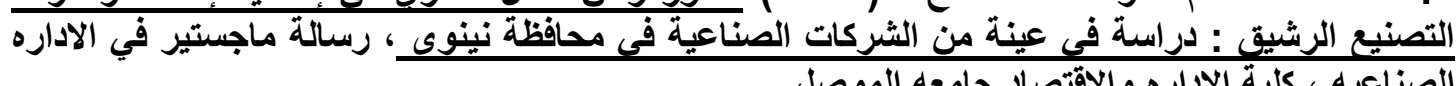

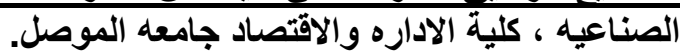



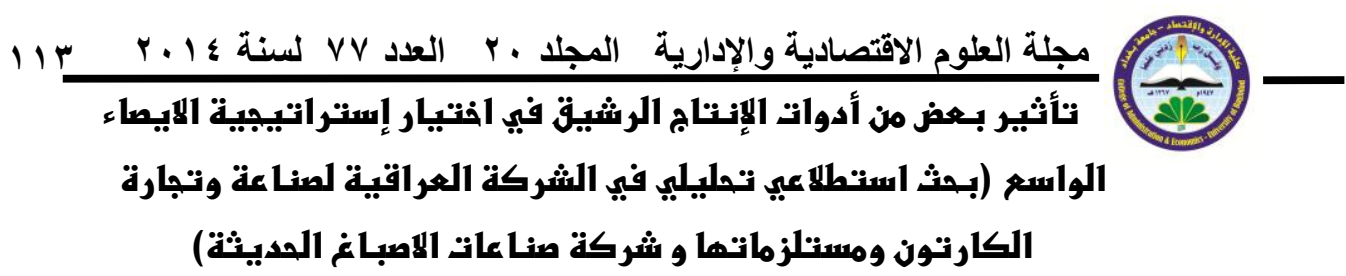

7. ABIDIN, WAN MUHAMMAD SHUKRI BIN WAN ZAINAL , (2008), IMPLEMENTATION OF LEAN PRACTICES IN SMALL AND MEDIUM ENTERPRISE , A report submitted in partial fulfillment of the requirements for the award of the degree of Bachelor of Mechanical Engineering, Faculty of Mechanical Engineering UNIVERSITI MALAYSIA PAHANG

8. Alapieti , Tytti , (2012), CREATING AN EFFICIENT AND SCALABLE MANUFACTURING SYSTEM FOR CUSTOMIZED MADE-TO-MEASURE JEANS , Master of Science in the Automation, Mechanical and Material Engineering Faculties, TAMPERE UNIVERSITY OF TECHNOLOGY

9. Altonen, Aiste \& Altonen, Kalle ,( 2011), Success Factors of Mass Customization Cases: Chocri and Shoes of Prey, Master's Thesis in Departments of International Business and Management and Marketing 10. Barac, Nada \& Milovanović , Goran \& Andjelković ,(2010), Aleksandra , LEAN PRODUCTION AND SIX SIGMA QUALITY IN LEAN SUPPLY CHAIN MANAGEMENT , Economics and Organization Vol. 7, No 3 , pp. 319 334

11. Chandrasekaran , K. ,( 2011), Lean Manufacturing Techniques In Jewellery Industry, JANUARY

www.solitaireinternational.com/.../2802115210indus...

12. Christensen , Kasper Hovgaard,(2012), Mass Customization: An analysis of planning and control issues and solutions in operations when a market demands increasing flexibility , Department of Economics and Business Bachelor Thesis, Aarhus University, Business and Social Sciences .

13. GOFORTH , KELLY ANN ,(2007) , ADAPTING LEAN MANUFACTURING PRINCIPLES TO THE TEXTILE INDUSTRY, A thesis submitted to the Graduate Faculty of North Carolina State University in partial fulfillment of the requirements for the Degree of Master of Science , Raleigh, North Carolina

14. Hawkins, Lisa \& Knowledge, Pera ,(2001), Fundamental Productivity Improvement Tools and Techniques for SMEs , PRIME Faraday Partnership Wolfson School of Mechanical and Manufacturing Engineering Loughborough University, Loughborough, Leics LE11 3TU

15. Heizer, Jay \& Render, Barry ,(2008), Principles of operations management , Seventh Edition, Prentice Hall , Inc., New Jersey

16. Kissimoto, Kumiko Oshio\& Laurindo ,Fernando José Barbin ,(2010) , Information Technology as an Enabler for Mass Customization Strategy: Integrating Customer and Organization, PICMET 2010 TECHNOLOGY MANAGEMENT FOR GLOBAL ECONOMIC GROWTH

17. Krajewski , Lee J. \& Ritzman , Larry P. \& Malhotra , Manoj K. ,(2010), Operations Management - Processes and Supply Chains , (ninth) Global Edition , Pearson Education, Inc., New Jersey

18. Marin-Garcia, Juan A. \& Carneiro, Paula ,(2010), Questionnaire validation to measure the application degree of alternative tools to mass production, 


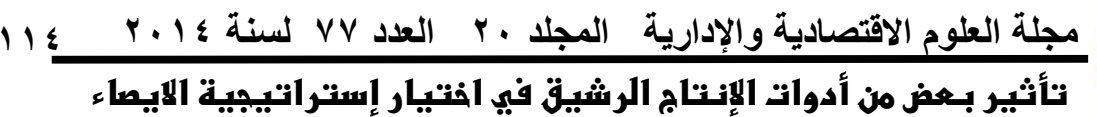

الواستر (بهث استتطلاعبي تمليلي في الثنركة العراقية لصناعة وتنجارة

الكارتون ومس1تتلزماتها و شُركة صناعات الاصباغ الصدبثنة)

International Journal of Management Science and Engineering Management, 5(4): 268-277

19. Matulík , Ing. Petr,( 2008) , Mass Customization, Doctoral Thesis , Tomas Bata University in Zlín, Faculty of Management and Economics .

20. NAHMENS, ISABELINA, (2007), MASS CUSTOMIZATION STRATEGIES AND THEIR RELATIONSHIP TO LEAN PRODUCTION IN THE HOMEBUILDING INDUSTRY, A dissertation submitted in partial fulfillment of the requirements for the degree of Doctor of Philosophy in the Department of Industrial Engineering and Management Systems in the College of Engineering and Computer Science at the University of Central Florida Orlando, Florida

21. Paneru , Naresh ,(2011), Implementation of Lean Manufacturing Tools in Garment Manufacturing Process Focusing Sewing Section of Men's Shirt, Master's thesis Autumn ,Degree Programme in Industrial Management Oulu University of Applied Sciences

22. Riihimaa, Jaakko \& Ruohonen, Mikko \& Mäkipää, Marko ,( 2004) , Transitions in Mass Customization Strategies- Requirements for Information Systems , FRONTIERS OF E-BUSINESS RESEARCH

23. Ristov, Pero \& Ristova, Ana Trpeska,(2011), WEB-BASED PRODUCT CONFIGURATION FOR MASS CUSTOMIZATION Towards developing mass customization strategy, Thesis Work, PRODUCTION SYSTEMS, School of Engineering in Jönköping in the subject area Production Systems. The work is part of the university's two-year master degree

24. Russe II , Roberta S. , Taylor III , Bernard W. ,(2000) , Operations Management - Multimedia Version , Third Edition , Prentice Hall , Inc., New Jersey

25. SAID , SHUHAIRY BIN , (2008) , LEAN MANUFACTURING IMPLEMENTATION FOR LOW VOLUME CAR PRODUCTION, A report submitted in partial fulfillment of the requirements for the award of the degree of Bachelor of Mechanical Engineering with Automotive Engineering, Faculty of Mechanical Engineering UNIVERSITI MALAYSIA PAHANG

26. Silveira, Giovani Da \& Borenstein, Denis \& S. Fogliatto, FlaHvio, (2001), Mass customization: Literature review and research directions , Int. J. Production Economics 72,1$\} 13$.

27. Stacks , Christopher \& Jeffrey M. Ulmer, Ph.D., ASQ-CMQ/OE ,2009, Applied Lean Thinking: General Usage Principles, the Technology Interface Journal/Spring, Volume 9 No. 2

28.Steiner, Frank \& Piller, Frank\& Zangitu, Martin \& Castellano ,( 2012), Mass Customization Strategies,

http://scholar.google.com/scholar? $q=$ Mass + Customization+Strategies\&hl=ar\&as $s$

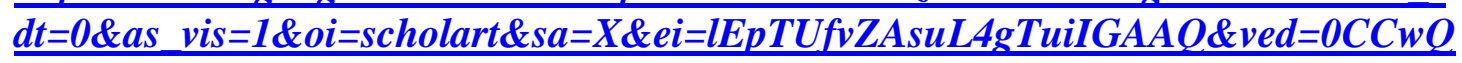
$g Q M w A A$

29. Stump , Gregory Brandon,(2008), AN INTEGRATED FRAMEWORK FOR APPLYING LEAN MANUFACTURING AND OTHER STRATEGIES IN MASS CUSTOMIZATION ENVIRONMENTS , University of Kentucky Master's Theses. Paper 563 


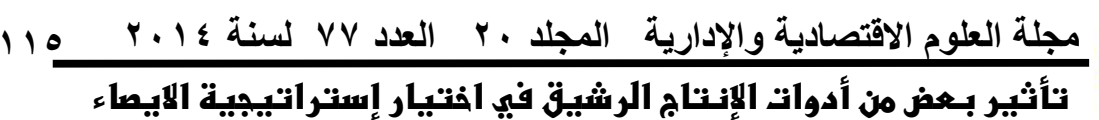

الواستر (بهث استتطلاعبي تمليلي في الثنركة العراقية لصناعة وتجارة

الكارتون ومسستلزماتها و شُركة صنا عات الاصباغ الصدبثنة)

\title{
The Effect of Some Lean Production Tools in selecting a Mass Customization Strategy
}

\begin{abstract}
:
The research aims to indicate the relationship between lean production tools included seven \{constant improvement, and Just in time (JIT), and the production smoothing, and quality at the source, and standardized work, Visual management, and activities 5S \} and Mass Customization strategy for the model (Pine \& Gilomer, 1997) \{collaborative, adaptive, cosmetic, transparent\}, as well as providing a conceptual framework and applied for variables search to clarify how they will choose a Mass Customization strategy through the lean production tools, and recognize the reality of the practices of Iraqi industries in such a field. Moreover, aims to highlight the positive aspects that accrue to companies as a result of reliance on modern technologies and systems in production and a rapid response to the needs and desires of customers.

It was the application in Al-Asbaagh Al-Hadetha industries company and the Iraqi company for carton manufacturing and trade and supplies, it was used questionnaire to collect data from the research sample consisting of 58 people from the employees of the two companies, There positions functional were (Administrator of the Commissioner, the Director, Deputy Director, technical supervisor, head of observers) and used the methods of statistical analysis (descriptive statistics, correlation analysis, regression analysis ) to analyze the questionnaire and the results showed the existence of a correlation between lean production tools and Mass Customization strategy, as well as having an impact also among the two companies and prove all the research hypotheses. Recommendations have been proposed in the light of this, the most important benefit from the availability of lean production tools to enhance Mass Customization strategies and strategic choice for being more cooperative strategies appropriate for context two companies Alambhuthtin the work.
\end{abstract}

Key words : lean production tools, Mass Customization strategy • 